\title{
LA FACILIDAD PROBATORIA EN EL PROCEDIMIENTO DE TUTELA LABORAL. CONSTITUCIONALIDAD Y TRAMITACIÓN PROCESAL
}

\author{
FRANCISCO JARA BUSTOS ${ }^{*}$ \\ Universidad de Chile
}

\begin{abstract}
RESUMEN: El procedimiento de tutela laboral introdujo en el artículo 493 del Código del Trabajo un principio de facilidad probatoria. Al respecto se han suscitado muchas discusiones acerca de la constitucionalidad de esta norma en relación a la regla general de carga de la prueba del artículo 1698 del Código Civil. El presente trabajo intenta responder algunas críticas a esta institución, desde la perspectiva de la dogmática procesal civil. Se analizan los principios que han guiado las reformas procesales civiles, así como la importancia del derecho a la prueba y sobre quién debe recaer la carga de la misma. Luego se ofrecerá una conceptualización de la inversión probatoria, y de algunos criterios relevantes sobre la materia en el derecho nacional y comparado para sostener que es plenamente compatible con un Estado democrático de Derecho. Asimismo se intentan responder las críticas sobre la tramitación procesal de esta norma, proponiendo una interpretación plenamente compatible con la Constitución y el debido proceso.
\end{abstract}

Palabras clave: carga de la prueba, facilidad probatoria, cargas probatorias dinámicas, prueba indiciaria, indicios suficientes, tutela laboral, nueva justicia laboral.

\begin{abstract}
A principle that facilitates the efforts of proof was introduced by labor guardianship proceedings in the article 493 of the Chilean Labor Code. In this regard much discussion has held about its constitutionality, relating to the general rule of burden of proof, according to Chilean Civil Code Article 1698. The object of this paper is to answer critics to this institution from the perspective of Civil Procedure doctrine.

To accomplish this, the work analyzes principles that had guided the civil procedural reforms, along with the relevance of the right of proof, and on whom should have the burden of proof. The paper includes a conceptualization of change of burden of proof and some relevant criteria to the subject in both national and compared laws to affirm this institution is fully compatible with a democratic rule of law. Also, the paper is aimed to answer the criticism about the legal proceedings of this rule, offering an interpretation according to both Chilean Constitution and due process of law.
\end{abstract}

Key words: burden of proof, facility of proof, dynamics burdens of proof, evidence proof, sufficient evidence, labor guardianship, new labor justice.

\footnotetext{
* Ayudante de las cátedras de Historia del Derecho, Historia Institucional de Chile y colaborador del Departamento de Derecho del Trabajo y de la Seguridad Social de la Universidad de Chile. Correo electrónico: franciscojara1@gmail.com). Este artículo es una versión mejorada de la ponencia presentada bajo el título "La Facilitad probatoria en el procedimiento de tutela laboral y su constitucionalidad" en el "Primer Congreso Nacional Estudiantil de Derecho del Trabajo" realizado en junio de 2010 en la Universidad de Concepción. El autor agradece comentarios a esa versión preliminar realizados por los profesores Raúl Núnez Ojeda y Pablo Bravo Hurtado, quienes me dieron algunas orientaciones, así como han sido quienes me han permitido tener una visión más amplia del derecho procesal y las reformas a la justicia. Tampoco puedo dejar de agradecer al profesor Claudio Palavecino Cáceres, tanto por motivarme a presentar el artículo en Concepción, por las discusiones que hemos tenido sobre estos temas, como por ayudarme a revisar distintos borradores de este trabajo. Asimismo agradezco al profesor Eric Palma González por sus comentarios metodológicos sobre un primer borrador de este trabajo. Por último, quiero agradecer a mi amigo Claudio Tapia Alvial por haberme hecho algunos comentarios estilísticos sobre uno de los últimos borradores. No obstante lo anterior, cualquier error en estas páginas es de exclusiva responsabilidad del autor.
} 
Los libros no son hechos para que créamos lo que dicen, sino para ser analizados. GUILLERMO DE BASKERVILLE

\section{PRELIMINARES ${ }^{1}$}

La carga de la prueba entendida en los términos del artículo 1698 del Código Civil chileno, constituye para muchos uno de los pilares sobre los que se estructura el Estado de Derecho. Por esta razón resulta problemático para un sector de la doctrina nacional el que la reforma a la justicia laboral contemple en el procedimiento de tutela de los derechos fundamentales, una regla de facilidad probatoria en el artículo 493 CT, que algunos han identificado con las cargas probatorias dinámicas. Asimismo, contiene disposiciones relativas a la modificación de la carga probatoria en atención a su facilidad o disponibilidad el proyecto de Código Procesal Civil que actualmente se tramita en el Congreso Nacional.

En el Derecho comparado el reconocimiento de la desigualdad respecto al acceso a los medios de prueba, ha llevado a desarrollar distintas instituciones para asegurar el adecuado desenvolvimiento de algunos procesos, toda vez que, en muchos casos, las distintas partes no se encuentran en pie de igualdad, sea porque tienen diferentes grados de control sobre el medio de prueba o el entorno donde se produjo, por dispares condiciones socioeconómicas, por tener distintos grados de conocimientos respecto a ciertas áreas o procesos productivos, etc. Por esta razón nuestra legislación y nuestra práctica jurídica cada vez admiten más hipótesis donde es posible aplicar principios de facilidad probatoria.

En este trabajo nos propondremos responder algunas de las críticas que han expresado algunos profesores nacionales a lo que identifican como inversión probatoria en el procedimiento de tutela laboral. Estructuraremos nuestro análisis, en tres partes. En la primera haremos algunas reflexiones sobre las reformas a la justicia, (i) comenzando con una reflexión acerca de los principios que han orientado las reformas en nuestro país y cómo la reforma a la justicia laboral no puede ser adecuadamente comprendida si no se atiende a la reforma a la justicia civil en su conjunto, (ii) revisaremos la importancia del rol del juez y su relación con la búsqueda de la verdad, (iii) veremos si es posible hablar en nuestro sistema de la existencia de un derecho a la prueba con el objeto de configurar un marco de garantías aplicables.

La segunda parte permitirá considerar cómo la facilidad probatoria es compatible con la existencia de determinadas garantías. Para eso revisaremos: (i) la carga de la prueba; (ii) las críticas a la inversión probatoria en el proceso laboral; (iii) los pronunciamientos de los académicos nacionales sobre la institución; (iv) seguiremos con una revisión a estándares comparados de facilidad e inversión probatoria y derecho a la prueba; (iv.i) deteniéndonos especialmente en el derecho español para rastrear la genealogía de nuestro procedimiento laboral; (v) para luego revisar criterios chilenos sobre modificación de la carga probatoria;

\footnotetext{
${ }^{1}$ Para efectos de este trabajo utilizaré algunas abreviaturas normativas, la mayoría de ellas comunes en la práctica chilena. Así el Código Civil (CC), Código del Trabajo (CT), Código Orgánico de Tribunales (COT), Código de Procedimiento Civil (CPC), Código Procesal Penal (CPP), la Constitución Política de la República (CPR), y la Ley 19.968 de Tribunales de Familia (LTF). Adicionalmente haré referencias al Proyecto de Código Procesal Civil (PCPC) actualmente en tramitación. Este se encuentra disponible junto al Anteproyecto del mismo (ACPC) en el sitio web del Ministerio de Justicia: www.minjusticia.cl.
} 
(vi) finalmente, criticaremos una objeción sobre la existencia de la presunción de inocencia en materia procesal civil.

Por último, responderemos las objeciones respecto de la tramitación que se han señalado, proponiendo una interpretación adecuada de la norma que la hace plenamente compatible con la Constitución y las garantías del debido proceso.

\section{LOS PRINCIPIOS DE LAS REFORMAS A LA JUSTICIA}

Nuestro país se encuentra inmerso en un amplio proceso de reformas a la justicia. Entre los principales objetivos de las reformas, junto con afianzar el modelo constitucional, y adecuar normas procesales a las exigencias del tráfico moderno, se encuentra el garantizar el acceso democrático a la justicia. En palabras de Mauro Cappelletti, "el acceso a la justicia debe considerarse como un derecho humano de importancia primordial"2. Cappelletti, a través de uno de los proyectos de análisis de derecho comparado más grandes realizados, constató una gran "pobreza legal", entendida como "la incapacidad de muchas personas para hacer cabal uso de la ley y de sus instituciones"3. Por lo tanto, lograr un acceso igualitario a la justicia debe ser una de las principales metas de las regulaciones procesales ${ }^{4}$. Otro de los componentes del acceso a la justicia debe ser que se logren resultados, lo que no significa simplemente el llevar a un término el litigio, obtener una resolución judicial, o cualquier tipo de resultados, sino lograr resultados justos, pues "solamente la obtención de decisiones jurídicamente correctas es la garantía que sustenta la prohibición general de la autotutela" 5 .

El acceso a la justicia se considera como un deber constitucional del Estado. Esto significa que el legislador debe tomar sus decisiones considerando el acceso a la justicia como un "mandato de optimización respecto a posibilidades jurídicas y fácticas" 6 , es decir, como directivas que deben informar la acción de los legisladores y que pueden servir como principios interpretativos. Asimismo, los procesos deben estar guiados por principios procesales 7 que permitan lograr el objetivo de garantizar el acceso a la justicia.

\footnotetext{
${ }^{2}$ CAPElletir, Mauro y GaRTH, Bryant. El acceso a la justicia. La tendencia en el movimiento mundial para hacer efectivos los derechos. México: Fondo de Cultura Económica, 1996. p. 11.

${ }^{3}$ Ibid. Nos referimos al Proyecto Florencia para el Acceso a la Justicia.

${ }^{4}$ Ver en general los proyectos de ley, las discusiones y los mensajes de las reformas procesales.

5 Seguimos aquí a: NúNÉEZ OjEDA, Raúl. "El sistema de recursos procesales en el ámbito civil en un Estado democrático deliberativo", en: Ius et Praxis, vol. $14 \mathrm{~N}^{\circ} 1$, p. 203. Talca: Universidad de Talca, 2008.

${ }^{6}$ En el sentido que le da Alexy, respecto a la diferenciación entre reglas y principios. Véase ALEXY, Robert. Teoría de los Derechos Fundamentales. Madrid: Centro de Estudios Constitucionales, 1993. p. 99.

7 NúNez OJEDA, Raúl. "Crónica sobre la Reforma al Sistema Procesal Civil Chileno (Fundamentos, Historia y Principios", en: De la Oliva Santos, Andrés y Palomo Vélez, Diego (coord.). Proceso Civil. Hacia una nueva justicia civil. Santiago: Editorial Jurídica de Chile, 2007, p. 681. Sobre los principios véase respecto a la reforma procesal civil, véase además de la obra citada; Maturana, Cristián. "Los Principios que deben regir un Nuevo Proceso Civil en Chile", en: Boletín Jurídico del Ministerio de Justicia. Hacia una Nueva Justicia Civil, año 4, $N^{\circ} 7$, noviembre 2005, pp. 10-21. Sobre los principios en el proceso laboral puede consultarse: VV.AA. Derecho Procesal del Trabajo. Treinta Estudios. Montevideo: Fundación de cultura universitaria, 2005. (en particular la primera parte). Para el caso chileno particular, ver: OTAROLA, Paulo. "Los Principios Formativos del Proceso y el Rol del Juez en el Proceso Laboral Chileno", en: Primera Jornada Chileno-Uruguaya de Derecho del Trabajo y de la Seguridad Social, Montevideo Uruguay, junio 2008. Se hace la prevención de que este trabajo no se basa principalmente en los principios laborales, sino en buscar una respuesta desde la dogmática procesal civil.
} 
Francisco Javier Jara Bustos / La facilidad probatoria en el procedimiento de tutela laboral..

Desde la reforma procesal civil austríaca de 1875 -la reforma que ha ejercido más extenso influjo en la época moderna ${ }^{8}$ - se ha comenzado a entender que el proceso afecta también a la sociedad, por lo que los conflictos deben ser solucionados tan rápida, económica y pacíficamente como sea posible, lo que solo puede lograrse si el juez tiene posibilidad de influir sobre la marcha del procedimiento. Progresivamente los sistemas tienden a procesos orales, con inmediación, concentración, publicidad ${ }^{9}$ y con el principio dispositivo entendido como disposición del objeto del conflicto, entregando al juez la obligación de hacerlo avanzar, impidiendo dilaciones innecesarias y actuaciones de mala fe.

Previo a la reforma austríaca, toda la legislación procesal civil entendía el principio dispositivo en dos vertientes: la primera correspondiente a la facultad de las partes de disponer sobre la controversia jurídica ${ }^{10}$, facultad que hoy se mantiene. Sin embargo, se alteró sustancialmente el principio dispositivo entendido, en su segunda vertiente, como facultad de las partes para determinar la continuación del pleito. El impulso procesal de oficio entrega al tribunal el impulso y la dirección del proceso $^{11}$, lo que termina con el pernicioso abandono del procedimiento ${ }^{12}$, que se traduce en una resolución más expedita de los conflictos. Gracias a esto se limita una estrategia dilatoria, que no es inocua, sino por el contrario puede ser muy'dañina para una de las partes. Si el proceso se analiza desde el punto de vista de los intereses, "actor es aquel que postula una determinada modificación de la realidad empírica; demandado quien postula un mantenimiento del statu quo"13, ocurriendo que quien se vea favorecido por el estado de las cosas siempre apostará a favor de una estrategia dilatoria del proceso, dado que el proceso no permite, parafraseando a Italo Andolina una "tregua de justicia"14 que desactive los procesos que se desarrollan en la realidad histórica donde la posición del actor va progresivamente deteriorándose a costa de la del demandado. Por esta razón, se puede sostener que la novedad fundamental del sistema se relaciona con dotar al juez de mayores poderes de dirección del procedimiento, que le permitirán adoptar de oficio las medidas que considere pertinentes para el desarrollo pronto, eficaz y sin dilaciones, de modo de evitar su paralización. Así, se reduce la ventaja obvia que producen las dilaciones, vale decir, el permitir negociaciones extraprocesales poco beneficiosas para las partes más vulnerables.

\footnotetext{
8 SCHÖNKE, Adolfo. Derecho Procesal Civil. Barcelona: Bosch Casa Editorial, 1950, p. 15.

${ }^{9}$ Que son la nota común en las reformas anteriores en materia penal, laboral y de familia. Por ejemplo, en el ámbito laboral se reconoce que los principios que informan la Reforma a la Justicia Laboral son inmediación, impulso procesal de oficio, celeridad, buena fe, bilateralidad de la audiencia y gratuidad -artículo 425 CT-.

${ }^{10}$ NÚNẼ OJEDA, Raúl. "Crónica sobre la Reforma... (n. 7), p. 682.

${ }^{11}$ Ibid. También Maturana, Cristíñ, op. cit. (n. 7), p. 16.

12 Se consagra el impulso procesal de oficio en el artículo 425 CT y en el artículo 4 PCPC. La ley de Tribunales de Familia contempla el abandono del procedimiento -artículo $21 \mathrm{LTF}$-, sin perjuicio de tener como principio el impulso procesal de oficio -artículo 9 LTF-. Sin embargo, creemos que esto se debe a la posibilidad de desistir de las partes, ya que es un conflicto más personal que otros. Así, no concurriendo ninguna a audiencia fijada, y no solicitando fecha para una nueva se entiende abandonado el procedimiento. Con todo el abandono del procedimiento no rige en causas donde existe un interés superior -acorde a sus principios; v. gr. artículo 16 LTF-, como en causas de menores, filiación, maltrato infantil, violencia intrafamiliar.

13 ANDOLINA, Italo. "Cognición" y "Ejecución Forzada" en el Sistema de la Tutela Jurisdiccional. Lima: Communitas, 2008, p. 26. La anticipación de la tutela sin duda será un tema de creciente interés por los conflictos que la institución puede suscitar. ${ }^{14}$ Ibid. p. 27.
} 
Ahora bien, uno podría preguntarse, ¿por qué tantas reflexiones a propósitos de la justicia civil, si este trabajo es acerca de la justicia laboral? En primer lugar, porque una adecuada comprensión del derecho - procesal civil ${ }^{15}$ - debe permitir integrarlo e interpretarlo coherentemente. Si consideramos que los problemas de acceso a la justicia fueron el motivo de la reforma procesal laboral, y que los procesos laborales se remitían a versiones simplificadas de los procedimientos civiles, el preguntarnos por el sistema civil cobra mayor relevancia. En este punto, la literatura laboralista fue muy crítica de la situación del acceso a la justicia, a diferencia de la dedicada al procedimiento civil ${ }^{16}$. Las críticas del laboralismo al proceso laboral antiguo apuntaban principalmente a la necesidad de cambiar el esquema del proceso, aduciendo que los principios que lo informaban no eran compatibles con el principio "tutelar laboral"17, ni con la protección de los derechos constitucionales laborales, como tampoco con los inespecíficos que constituyen la llamada "ciudadanía en la empresa"18.

Nos parece que la crítica de los laboralistas a los procedimientos antiguos iba -al menos parcialmente- mal apuntada. Una adecuada reforma a la justicia laboral, o de cualquier índole no implica solo generar un procedimiento especial para trabajadores y empleadores que sea sustancialmente distinto al modelo general, y que el resto de la sociedad se las arregle como pueda ${ }^{19}$, sino más bien debería generar un sistema procesal que permita un acceso igualitario a la justicia a toda la sociedad, sin perjuicio de que cada proceso puede adecuarse además para proteger ciertos intereses específicos.

Por lo mismo, seguro que de haber estado vigente el proyecto de Código Procesal Civil, el autor que se lamentaba que tuviéramos un "sistema procesal del trabajo tan lamen-

\footnotetext{
${ }^{15}$ Los procesos civiles que -en sentido amplio- podemos entender como aquellos que no son parte del proceso penal, que es condición para el ejercicio del ius puniendi estatal. Así procesos civiles comprenderá entre otros, el proceso civil, el de familia y laboral. Debemos comprender la función integradora y supletoria que cumple la legislación procesal civil -en sentido estrictoen todos los ámbitos; v. gr. entre otros, los artículos 52 y 353 CPP, 432 y 474 CT, 27 y 67 LTF que establecen el carácter de las normas procesales civiles en cuanto a disposiciones comunes y recursos, entre otras materias. Si bien se establece que estos principios serán aplicables solo en la medida en que no vayan contra los principios y la naturaleza de las instituciones a las que se deben arrimar supletoriamente, en la práctica resulta difícil la interacción entre sistemas con principios informadores tan distintos. Por lo mismo, una vez consagrada la reforma procesal civil no nos cabe duda que se permitirá una mejor comprensión del derecho procesal chileno en su conjunto.

${ }^{16}$ Se constata que no son muchos los textos de estudio chilenos que critican el modelo de justicia civil y que incluso llegan a un análisis positivo del mismo. Véase NÚÑEZ OJEDA, Raúl. "Crónica sobre la Reforma... (n. 7), p. 678.

${ }_{17}$ MacChiavello, Guido. Manual de Derecho Procesal del Trabajo. Santiago: ConoSur, 1997, p. 15.

También criticaba que no todo el país existiera una jurisdicción especializada, pues en algunos territorios del país estos casos eran conocidos por jueces civiles. (pp. 18 y ss.)

${ }^{18}$ Este concepto alude a la protección ya no solo de los derechos laborales propiamente tales, sino a la protección de los derechos civiles y políticos del trabajador como ciudadano (también llamados derechos laborales inespecificos) que tradicionalmente se entiende quedan disminuidos en la relación laboral producto de la potestad de mando del empleador. Sobre el particular consúltese: Gamonal, Sergio. El Procedimiento de Tutela de Derechos Laborales. Santiago: LegalPublishing, 2008, pp. 7 y ss. UGARTE CATALDo, José Luis. "La Tutela de Derechos Fundamentales y el Derecho del Trabajo: de Erizo a Zorro", en: Revista de Derecho vol. 20 No2, p. 66. Valdivia: Universidad Austral de Chile, diciembre 2007.

${ }^{19} \mathrm{Se}$ ha identificado por algunos autores en esta tendencia de generar diversos estatutos privilegiados, una crisis de coherencia. Esto porque si bien estos ordenamientos mejoran la satisfacción de los derechos de ciertos sujetos, tiene efectos críticos sobre el sistema globalmente entendido, puesto que es un indicio de la disfunción que se produce del proceso general. La idea expuesta aquí sobre crisis de coherencia, en: TARUFFO, Michele. "Racionalidad y crisis ley procesal", en: DOXA No 22, pp. 310-320, Alicante, 1999.
} 
Francisco Javier Jara Bustos / La facilidad probatoria en el procedimiento de tutela laboral...

tablemente civil" 20 se habría dado cuenta que el problema no es necesariamente la adopción de parámetros "laborales" en el proceso, sino que cambiar una estructura procedimental en desuso, por una acorde a las necesidades del mundo actual. Creemos que por eso es importante reiterar que la reforma laboral se da dentro de un marco mayor de reformas. Del mismo modo, la crítica que actualmente hacen sectores ligados al mundo empresarial a los nuevos procesos laborales, que señala que estos principios son obra del laboralismo progresis$t a$, también debería -al menos- replantearse.

\subsection{ROL DEL JUEZ Y LA BÚSQUEDA DE LA VERDAD}

Sabemos que existe una tendencia a dar mayores poderes al juez, quien "ya no es un personaje detrás de expedientes" ${ }^{21}$, sino que adquiere un papel de conducción preponderante. Corresponde mencionar brevemente las facultades del juez en relación a su función, su relación con la prueba y sus facultades probatorias en un Estado de Derecho.

Seguimos a Raúl Núñez Ojeda cuando señala que para esto es fundamental entender la diferencia entre los discursos de fundamentación o justificación y discurso de aplicación o de adecuación en la argumentación jurídica 22 . "El primero tiene por objeto justificar la validez o corrección de una norma" ${ }^{23}$, es decir, atiende a su validez en abstracto. Posterior a esa consideración, entra en juego el discurso de aplicación o adecuación, que "se refierè a la corrección de la decisión jurídica, en la cual hay que establecer si la norma prima facie aplicable es adecuada a una situación determinada, para lo que es necesario tener en cuenta todos los datos que caracterizan a esa situación, es decir, la situación de aplicación" ${ }^{24}$. Interpretar la ley para el caso concreto y fundamentar las sentencias - no enunciarlas o explicarlas- es parte fundamental del concepto de jurisdicción ${ }^{25}$.

Las exigencias de decidir conforme a la ley y de justificar correctamente ${ }^{26}$ se constituyen en límites a la discrecionalidad de los órganos jurisdiccionales, tema sumamente relevante para la sociedad en su conjunto, en particular dentro de nuestra tradición jurídi$\mathrm{Ca}^{27}$ donde existe una gran desconfianza hacia los jueces. En este sentido, para analizar una

\footnotetext{
20 PUlGar, Carlos. “¿Existe un Derecho Procesal del Trabajo?”, en: Boletín Oficial de la Dirección del Trabajo N ${ }^{\circ} 2005$, p. 8. Santiago, febrero 2006. Encuentro que esa sola frase engloba en forma genial toda la crítica del laboralismo a los procesos antiguos.

21 Pérez Ragone, Álvaro y NúNÉz, Raúl. "Nuevo Código Procesal Civil: un proyecto que acerca y simplifica la justicia". Junio 2009. [En línea] http://www.derecho.ucv.cl/jciviljun09.pdf [Consulta 20.01.2010].

22 Véase también, GÜNTHER, Klaus. "Un concepto normativo de coherencia en una teoría de la argumentación jurídica", en: DOXA $\mathrm{N}^{\circ} 17-18$, pp. 271-302. Alicante, 19.95.

${ }^{23}$ NúŃEZ OJEDA, Raúl, “El sistema de recursos... (n. 5), p. 202.

24 Ibid.

${ }^{25}$ NúN̄EZ OJEDA, Raúl, “El sistema de recursos... (n. 5), p. 200.

${ }^{26}$ Puede ocurrir que en un determinado caso una norma sea anulable, pero también en este caso no cualquier órgano puede pronunciarse sobre el tema. Así, ATRIA, Fernando. "El derecho y la contingencia de lo político", en: DOXA N" 26, p. 321. Alicante, 2006.

${ }^{27}$ Sobre la tradición del civil law, además de la obra de J. Merryman consultar en los artículos de TARUFFO, Michele. "El proceso civil de "civil law": Aspectos fundamentales", en: Ius et Praxis vol. 12 N 1, pp. 69-94. Talca, 2006 y de STÜRNER, Rolf. Derecho procesal y culturas jurídicas, en: Ius et Praxis vol. $13 \mathrm{~N}^{\circ} 1$, pp. 435-462. Talca, 2007. Una de las características que los autores notan sobre nuestro proceso civil es una excesiva desconfianza en los jueces y la búsqueda por controlarlos, desde la revolución francesa.
} 
Francisco Javier Jara Bustos / La facilidad probatoria en el procedimiento de tutela Laboral...

decisión entonces no solo basta verificar que sea posible hacer aplicación de determinados enunciados jurídicos, sino las razones dadas a favor de su aplicación frente a otros aplicables, determinando correctamente su significado y consecuencias jurídicas ${ }^{28}$.

Del hecho que una norma parezca aplicable no se sigue que la norma lo sea mecánicamente, sino que "quien aduce una razón tal debe poder demostrar que en caso de duda es compatible con todas las demás normas aplicables prima facie en dicha situación" ${ }^{29}$. El uso de adecuadas fundamentaciones ${ }^{30}$, es de esencial importancia. Con todo, la mayoría de las veces se requerirá un paso previo, consistente en determinar qué afirmaciones sobre hechos se deben tener por ciertas. Se recurre a prueba, entonces, en los casos en que existen proposiciones o afirmaciones sobre hechos controvertidas ${ }^{31}$.

La valoración de la prueba no es un tema exento de polémicas. Las reformas a la justicia han tendido a terminar con los sistemas de prueba legal tasada donde el adjudicador no puede valorarla de manera distinta ${ }^{32}$, por lo que resulta prácticamente imposible que la consecuencia jurídica determinada por la norma concuerde con lo que realmente ocurrión ${ }^{33}$. ¿Por qué se ha abandonado este sistema a favor de buscar esclarecer los hechos? La verdad acerca de las afirmaciones sobre hechos realizadas por las partes es un tema capital para la protección de los derechos; ¿la razón? Si entendemos que lo deseable de un sistema judicial es la producción de decisiones justas ${ }^{34}$, es obvio que uno de los presupuestos esenciales para

\footnotetext{
${ }^{28}$ En este sentido: NÚÑEZ OJEDA, Raúl, "El sistema de recursos... (n. 5), p. 201.

${ }^{29}$ GUNTHER, Klaus, op. cit. (n. 22), p. 284.

30 Siguiendo esta distinción sobre la expresión de la ley -formulada por Savigny-, Fernando Atria señala que la corrección de la expresión de la ley es una forma de interpretarla. No debe confundirse esto con la corrección de la ley, que equivale a torcerla. Asi: ATRIA, Fernando. "Jurisdicción e independencia judicial: el Poder Judicial como poder nulo", en: Revista de Estudios de la Justicia No 5, pp. 126 y ss. Santiago: Centro de Estudios de la Justicia, Facultad de Derecho, Universidad de Chile, 2004.

${ }^{31}$ Sobre diferencia entre probar hechos y probar proposiciones sobre hechos ver Manuel Serra Domínguez. El autor señala que es incorrecto que el objeto de la prueba lo constituyan los hechos, pues estos "entendidos como fenómenos exteriores al hombre en su acepción más general, son de una forma y no de otra, y como tales requieren prueba. Es imposible probar una mesa, un contrato, una obligación. Lo que sí requieren prueba son nuestras afirmaciones en relación con tales hechos. (...) Solo pueden ser probados, no los hechos, sino nuestros juicios existenciales o valorativos sobre tales hechos". SERRA DOMINGUEZ, Manuel. Estudios de derecho procesal. Barcelona: Ariel, 1969, p. 359. En el mismo sentido, se ha dicho que la afirmación de probar hechos, "es una expresión abreviada que hay que entender en su exacto significado. Nunca se prueban directamente hechos, lo que se prueban son siempre nuestras afirmaciones sobre diversos hechos". RAMOS MÉNDEZ, Francisco. Derecho procesal civil. Tomo I. Barcelona: JM Bosch, 1990, p. 531.

32 Taruffo, Michele. La Prueba de los Hechos. Madrid: Trotta, 2002, p. 343. Ver además Ferrer BeLTrÁN, Jordi. La Valoración Racional de la Prueba. Madrid: Marcial Pons, 2007, p. 62. Recordemos la desconfianza de la tradición continental respecto de los jueces y el interés por la seguridad jurídica.

${ }^{33}$ Así Ferrer Beltrán, Jordi. Prueba y verdad en el derecho. Madrid: Marcial Pons, 2002, pp. 52 y ss. Si no se asigna el valor tasado a la prueba, la sentencia será susceptible de impugnación.

${ }^{34}$ TARUfFo, Michele, "La Prueba... (n. 32), pp. 62 y ss. Existe una corriente que se opone a esta concepción de publicización del proceso. Son quienes se llaman a sí mismos "garantistas", quienes denuncian el origen autoritario de darle mayores poderes al juez cuyos mayores exponentes vivos son Adolfo Alvarado Velloso y Juan Montero Aroca. Una buena aproximación al problema se ve en: PICO I JUNOY, Joan. "El derecho procesal entre el garantismo y la eficacia: Un debate mal planteado", en: Montero Aroca, Juan (Coord.). Proceso civil e ideologia. Un prefacio, una sentencia, dos cartas y quince ensayos. Valencia: Tirant lo Blanch, 2006. El autor después de contrastar los principales puntos de vista que defiende el garantismo señala que el juez que con determinados límites "que vela por el respeto de la buena fe procesal o actúa una iniciativa probatoria (...), no es un juez fascista o autoritario, sino simplemente un juez comprometido en la obtención de la solución más justa posible de los conflictos. Probablemente por este motivo, en la mayoría de los ordenamientos procesales actuales de estados democráticos, así como en las propuestas internacionales que lege ferenda buscan la armonización del derecho procesal, se acoge este modelo de
} 
Francisco Javier Jara Bustos / La facilidad probatoria en el procedimiento de tutela laboral..

la correcta aplicación del derecho es que se consignen adecuadamente los hechos de la causa. Solo soluciones que apliquen correctamente las normas sobre enunciados fácticos tienen la legitimidad para ser jurídicamente admisibles en un Estado de Derecho.

Aquí compartimos una perspectiva cognoscitivista o epistemológica, que entiende que la actividad probatoria participa de los mismos esquemas y reglas racionales aplicables a cualquier actividad dedicada a la averiguación de hechos -posibilitada por la valoración libre de la prueba basada en la sana crítica-, de este modo la valoración de la prueba no es patrimonio exclusivo del derecho, sino de la racionalidad empírica ${ }^{35}$.

Al tener una afirmación por probada el juez debe incorporarla a su razonamiento decisorio y tenerla por verdadera ${ }^{36}$. Así, al afirmar que algo está probado equivale a afirmarlo como verdadero, por lo que "no habría diferencias entre las nociones de prueba y verdad" 37. Sin embargo, sabemos que existen limitaciones procesales y extraprocesales que impiden averiguar la verdad en todos los $\operatorname{casos}^{38}$, con todo pese a esos límites hay acuerdo en que "la búsqueda de la verdad tiene sentido" 39 . Con mayor razón debe considerarse que la búsqueda de la verdad debe ser $u n o^{40}$ de los objetivos del proceso, si solo el tribunal de instancia fija los hechos. De acuerdo con Taruffo "ninguna decisión correcta y justa se puede basar en hechos determinados erróneamente" 41 pero no se trata del objeto o el propósito final del proceso civil -como han acusado sus poco informados críticos- sino, "es solo la condición necesaria para una decisión apropiada, legítima y justa" 42 .

En vista de que la búsqueda de la verdad es uno de los objetivos del proceso, se justifica la necesidad de dotar al tribunal de poderes probatorios como ha venido propugnando la doctrina comparada desde hace tiempo. Sabemos que la iniciativa de las partes en muchos casos puede no ser suficiente para conducir al tribunal a la verdad sobre las afirmaciones

\footnotetext{
juez civil." p. 127. Parece asimismo atingente la respuesta de Taruffo a las críticas sobre el autoritarismo del proceso, al señalar que la conceptualización de estos autores es deficiente desde el punto de vista de la filosofía polítiça. La diferencia importante no sería entre autoritarismo y liberalismo sino lo la diferencia entre "Estado democrático y Estado autoritario", admitiendo cada uno de estos estados sistemas procesales con mayor o menos injerencia del principio dispositivo. Véase TARUFFo, Michele. "Poderes de las partes y del juez en Europa", en: DOXA N $\mathrm{N}^{\circ} 29$, pp. 251-254. Alicante, 2006.

35 GASCON ABELlAN, Marina. Los hechos en el derecho. Madrid: Marcial Pons, 2004, p. 60 y ss.

36 NúNEZ OjEDA, Raúl, "El sistema de recursos... (n. 5), p. 209.

37 "La prueba debe ser considerada como el medio a través del cual el Derecho pretende determinar la verdad de las proposiciones en el marco del proceso judicial." Así: TARUfFo, Michele. "Algunos comentarios sobre la valoración de la prueba", en: Discusiones $\mathrm{N}^{\circ}$ 3, pp. 86 y ss. Bahía Blanca, 2003. La misma idea en FERRER BELTRÁN, Jordi. "La valoración de la prueba", en: VV.AA. Estudios sobre la prueba. México: UNAM, 2006, pp. 32 y ss.

38 Obviamente las limitaciones humanas, los costos en dinero, en tiempo, los límites procesales a la admisibilidad de la prueba, protección de datos personales, u otros, pueden llevar a que se den por probadas afirmaciones que no se corresponden con la realidad, lo que ocurre también en muchos otros sectores de la experiencia que tampoco cuentan con todas las informaciones posibles; v. gr. la historiografía, la ciencia.

39 TARUFFo, Michele. "Algunas consideraciones sobre la relación entre prueba y verdad", en: Discusiones $\mathrm{N}^{\circ}$ 3, p. 37. Bahía Blanca, 2003. Para el autor, "un decisor racional debe tender a maximizar la verdad de su conocimiento sobre los hechos que le interesan, si quiere maximizar la validez de sus decisiones y reducir el riesgo de errores que puedan tráer graves consecuencias." ${ }^{40}$ Por supuesto, no es el único objetivo del proceso. De lo contrario no existirían reglas de exclusión, pese a eso parece que la crítica a la búsqueda de la verdad a toda costa es una de las banderas de los garantistas.

41 TARUfFo, Michele. La prueba. Madrid: Marcial Pons, 2010, p. 23.

42 lbid.
} 
discutidas $^{43}$, lo que repercute en el peligro concreto de que un litigante vea mermada su posibilidad de acceso a la justicia por encontrarse en una posición débilit ${ }^{4}$. El producir prueba oficiosa no implica expropiar a las partes de la facultad de realizar actividad probatoria, ya que los sujetos tienden a ser los mejores defensores de sus intereses ${ }^{45}$, y esta facultad debe ejercerse siempre respetando las garantías de las partes a discutir tanto la pertinencia como los resultados de esta prueba. Por lo mismo es igualmente claro que no se afecta la imparcialidad, pues el juez no decide predeterminadamente a quién favorecerá la prueba de oficio, pudiendo favorecer alternativamente a cualquier de los litigantes. En ese sentido han ido las reformas a los procedimientos civiles ${ }^{46}$.

La forma de valoración de la prueba que es funcional a esta perspectiva es la llamada valoración de acuerdo con las reglas de la sana crítica ${ }^{47}$. Este sistema otorga mayores facultades al juez para la valoración de la prueba, mediante el uso de ciertos parámetros de racionalidad para su justificación, lo que implica que su valoración de la prueba podría no llegar a la única decisión correcta, o que la conclusión sea necesaria ${ }^{48}$, como lo sería en el caso de la prueba legal tasada. Pero tampoco significa que la decisión queda entregada a la pura subjetividad del juez, teniendo "carta blanca" para desatar su arbitrio ${ }^{49}$. Esto se explica porque el razonamiento del juez en un sistema de sana crítica es susceptible de ser controlado ${ }^{50}$, pues las exigencias respecto de la justificación pueden verificarse respecto de cada uno de los medios de prueba, y en casos de no existir una razonabilidad o de haber justos motivos para apreciaciones diferentes, la decisión será revisable. Por lo mismo, la obligación de fundamentación es cada vez es más enfática en nuestra leyes.

\footnotetext{
43 Taruffo, Michele. "Investigación Judicial y Producción de Prueba por las Partes", en: Revista de Derecho vol. 15, p. 209. Valdivia: Universidad Austral de Chile, 2003. "No se puede esperar que las partes jueguen un papel cooperativo dirigido al descubrimiento desinteresado y objetivo de la verdad", sino que tienen por objeto ganar su caso a cualquier costo "y desde luego -si es necesario- al costo de la verdad".

${ }^{44}$ En algunos casos será "particularmente claro que estas facultades se confieren con el objeto de respaldar a la parte que no es capaz de desarrollar por sí misma una adecuada presentación de la prueba". Ibid.

${ }^{45}$ Las críticas a las potestades oficiosas alegan que las partes son quienes mejor defienden sus intereses; sin embargo en la medida en que el poder de prueba del tribunal no implica impedir el derecho a la prueba o el derecho a la defensa, nos parece que tiene poco sentido esta crítica. Igualmente se pronuncia HUNTER, Iván. Las potestades probatorias del juez de familia. Santiago: Legal Publishing, 2008. p. 41.

${ }^{46}$ Ver la LTF, y el CT con el libro V reformado, así como el ACPC y el PCPC.

47 También llamada libre valoración, es el sistema recogido por las reformas a la justicia, y en particular, por la procesal laboral. Véanse artículos 456 CT, 32 LTF, 297 CPP -este último no habla de sana crítica pero establece libre valoración con los límites de no contradecir los principios de la lógica, las máximas de la experiencias y los conocimientos científicos, lo que es lo mismo que sana crítica-. El PCPC lo consagra en el artículo 266. Obviamente existen casos donde las leyes exigen dar valoraciones determinadas en ciertas hipótesis -v. gr. instrumentos públicos- o excluir ciertas pruebas, pero lo enunciado constituye la regla general. Otras leyes también lo recogen, como la Ley de Juzgados de Policía local.

48 TARUfFo, Michele, La Prueba de... (n. 32), p. 294.

${ }^{49}$ A diferencia del sistema de "íntima convicción" que, pocas palabras, se refiere a una valoración discrecional, sin sujeción a reglas de alguna especie. La sana crítica en cambio implica un método objetivo de valoración, puesto que deben expresarse los motivos y las razones que convencen al juez de dar un determinado valor a cada prueba, estando sujeto a los conocimientos científicamente afianzados, las reglas de la lógica y las máximas de la experiencia.

${ }^{50}$ En este sentido NúNEZ OJEDA, Raúl, "El sistema de recursos... (n. 5), p. 216. Si no, no existiría mayor diferencia con la íntima convicción, que en esencia es incomunicable.
} 
Francisco Javier Jara Bustos / La facilidad probatoria en el procedimiento de tutela laboral...

\subsection{DERECHO A LA PRUEBA}

La actividad probatoria no se entiende simplemente como una carga procesal, sino que constituiría un derecho a la prueba ${ }^{51}$. Para Michele Taruffo se define "como el derecho de toda parte para producir toda la prueba relevante que esté en su posesión, para obtener la presentación de prueba relevante que esté en posesión de otras partes o de terceros, y que toda esa prueba sea debidamente considerada por el tribunal" 52 . Alex Carocca por su parte lo conceptualiza como "la garantía constitucional -o derecho fundamental- que asegura a todos los interesados la posibilidad de efectuar a lo largo del proceso sus alegaciones, sus pruebas y contradecir las contrarias, con la seguridad de que serán valoradas en la sentencia. En definitiva, se trata de la garantía de la participación de los interesados en la formación del juicio jurisdiccional" 53 . Con todo, estas garantías no implican que solo las partes individuales tengan un papel que jugar en el proceso civil ni el monopolio de la prueba ${ }^{54}$, pues de acuerdo con los fines del proceso y los planteamientos de la doctrina, el rol activo del tribunal le permitiría tomar decisiones informadas y más precisas" 55 .

El derecho a la prueba estaría recogido por nuestra Constitución dentro de las garantías procesales del artículo $19 \mathrm{~N}^{\circ} 3$ incisos 2 y 5 , al establecer la obligación de un procedimiento previo legalmente tramitado, y las garantías de un procedimiento e investigación racionales y justos. Puede entenderse como manifestación del derecho a defensa jurídica en la forma que la ley señale -establecido en el mismo artículo- en cuya virtud se le asegura a todas las personas el derecho a intervenir en el proceso de formación de la decisión jurisdiccional, formulando sus pretensiones y contradiciéndolas en un plano de igualdad. Además, por la incorporación de los Tratados Internacionales de derechos humanos al ordenamiento Constitucional según el artículo 5 inciso 2 CPR, se incluiría un amplio catálogo de garantías judiciales en nuestro ordenamiento ${ }^{56}$. Entre otras manifestaciones el derecho a la prueba de las partes incluiría: (i) el derecho a poder participar en la realización de prueba y estar informados sobre ella; (ii) a producir prueba dentro de un término probatorio; (iii) a hacerlo por medios idóneos de convicción; (iv) a pronunciarse sobre la pertinencia o relevancia de la prueba ofrecida, para evitar pruebas superfluas o prohibidas $^{57}$; (v) a examinar

\footnotetext{
51 PICO I JUNOY, Joan. El derecho a la prueba en el proceso civil. Barcelona: J.M. Bosch Editor, 1996, p. 448. No obstante esto nos referimos a la carga de la prueba en la sección siguiente.

52 TARUFFO, Michele. "Investigación Judicial... (n. 43), p. 209.

53 CAROCCA, Alex. "Una primera aproximación al Tema de la Prueba Ilícita en Chile", en: Ius et Praxis vol. 4 N 2 , p. 302. Talca: Universidad de Talca, 1998. Definición del autor, de su: Garantía constitucional de la defensa procesal. Barcelona: J. M. Bosch Editor, 1998, pp. 98 y ss. En el mismo sentido esta definición es compartida por JEQUIER, Eduardo. "La obtención ilícita de la fuente de la prueba en el proceso civil. Análisis comparativo del ordenamiento jurídico español y chileno", en: Revista Chilena de Derecho, vol. $34 \mathrm{~N}^{\circ} 3$, pp. 479 y ss. Santiago: Pontificia Universidad Católica de Chile, diciembre 2007.

54 PICO I JUNOY, Joan, El derecho... (n. 51).

55 TARUFFo, Michele, "Investigación Judicial... (n. 43), p. 209.

56 Garantía amplísima, que puede ser difícil de precisar. Véase CAROCCA, Alex. "Bases constitucionales del sistema procesal chileno", en: FERRADA BÓRQUEZ, Juan Carlos (Coord.). La constitucionalización del derecho chileno. Santiago: Editorial Jurídica de Chile, 2003. pp. 238 y ss.

57 Estas prohibiciones surgen porque el derecho a la prueba no es absoluto como ningún principio ni norma, ya que exige que se respeten ciertas formalidades para su validez, lo que significa que no debe haber "incurrido en determinadas prohibiciones que dicen relación con los denominados límites a la prueba". Así: CAROCCA, Alex, "Una primera aproximación... (n. 53), p. 305.
} 
y contradecir la prueba aportada por la contraparte; (vi) a producir contraprueba; (vii) a discutir su eficacia ${ }^{58}$.

Este derecho a la prueba requiere estar fundado sobre la base de la sana crítica $^{59}$. Solo la valoración racional puede ser aceptada o entendida, pues permite la revisión de la decisión si esta no es racional o si existen otras igualmente razonables.

Constitucionalmente, es posible armonizar la existencia de facultades oficiosas del juez con el respeto a estas garantías, ya que este sistema es plenamente compatible con el carácter social del Estado de Derecho, y con el deber constitucional de garantizar un procedimiento racional y justo. Esto pues, una de las dimensiones de un proceso racional y justo es asegurar la tutela efectiva de los intereses de las partes ${ }^{60}$. Ahora bien la actividad oficiosa del tribunal debe respetar los límites dados por el mismo derecho a la defensa. Por esto autores como Bordalí reconocen que el momento en que se plantean las medidas para mejor resolver del artículo 159 CPC -poco antes dictar sentencia- no es adecuado, porque genera una prueba que no permite ser discutida en el proceso, ni discutir su eficacia. Sin embargo las nuevas leyes procesales son plenamente compatibles con el derecho a la defensa y salvarían estas objeciones.

Asimismo, siempre que existan diversas interpretaciones posibles de las normas sobre prueba, se debe preferir aquella alternativa que respete el derecho a defensa, a producir y controlar la prueba, elementos fundamentales de todo debido proceso ${ }^{61}$.

\section{LA CARGA DE LA PRUEBA}

La conceptualización de la carga de la prueba no ha sido un tema pacífico en doctri$\mathrm{na}^{62}$, aun cuando - con seguridad-cualquier persona familiarizada con el derecho entiende o al menos conoce la formulación básica de esta regla. La respuesta a la pregunta, ¿a quién incumbe rendir la prueba? es lo que tradicionalmente se ha entendido que determina la carga de la prueba. Una mejor caracterización sería ¿a quién afecta negativamente el no rendir prueba sobre una afirmación? ${ }^{63}$, sin embargo a efectos del presente estudio bastará la concepción tradicional.

\footnotetext{
${ }^{58}$ Hemos revisado algunos criterios señalados por el profesor Carocca y el profesor Andrés Bordalí.

59 "(...) ante una valoración irracional de las pruebas por parte del juez, no sirve de mucho establecer el derecho de las partes a someterle todas las pruebas de las que disponen y que pueden servir para fundar la decisión sobre el hecho". TARUFFO, Michele, La Prueba de... (n. 32), p. 401.

${ }^{60}$ Sobre el caso español puede verse la justificación de PICO I JUNOY, Joan. El juez y la prueba. Estudio de la errónea recepción del brocardo iudex iudicare debet secundum allegata et probata, non secundum conscientiam y su repercusión actual. Barcelona: Bosch, 2007, p. 119. En el caso chileno puede verse la contundente respuesta de Andrés Bordalí a las objeciones "garantísticas" hacia constitucionalidad de las medidas para mejor resolver formulada por Hugo Botto. Véase BoRDaLf, Andrés. "El debido proceso civil", en: FERRADA BÓRQUEZ, Juan Carlos (Coord.). La constitucionalización del derecho chileno. Santiago: Editorial Jurídica de Chile, 2003, pp. 267-274.

61 En verdad uno de los propósitos del trabajo atiende a ver si el artículo 493 del CT también pasaría este test.

62 Rosenberg, Leo. La carga de la prueba. Buenos Aires: E.J.E.A, 1956, p. 49. Se ha postulado que se trataría de un derecho, un deber, una carga de afirmación.

63 Esto pues, cualquier parte puede probar incluso aquellas cosas que lo perjudiquen, o incluso sus pruebas pueden servir para respaldar afirmaciones de la contraria.
} 
Francisco Javier Jara Bustos / La facilidad probatoria en el procedimiento de tutela laboral...

Para una parte significativa de la doctrina la carga de probar recae sobre el demandante, basándose en el principio actori incumbit probatio, recogido por el artículo 1698 inciso 1 $\mathrm{CC}$, que fija la regla esencial en la materia al declarar que "Incumbe probar las obligaciones o su extinción al que alega aquellas o esta". Para Rosenberg esta sería la "espina dorsal del proceso civil"64.

Se ha sostenido que este principio es acorde con las necesidades de justicia y seguridad jurídica, pues debe probar el que sostiene una posición contraria al estado normal de las cosas, así la regla general consiste en que el que alega un hecho, sea demandante o demandado, debe probar ${ }^{65}$, ya que podría dejar al requerido en muchos casos en la situación de rendir una prueba diabólica, entendiendo por tal una prueba difícil o casi imposible de obtener, y permitiría que se presentaran muchísimas acciones sin fundamentos, toda vez que en este hipotético escenario sería el requerido quien debe probar su derecho.

La carga de la prueba muestra su mayor utilidad en aquellos casos en que el juez no logra la convicción a partir de los medios de prueba aportados en el proceso sea por las partes, o por el tribunal y las partes de acuerdo con la concepción que manejamos. En estos casos donde no se ha logrado probar la verdad acerca de las proposiciones sobre hechos de las partes, la carga de la prueba opera dando al adjudicador pautas para proceder. En palabras de Leo Rosenberg, las normas sobre carga de la prueba "son instrucciones dadas al juez acerca del contenido de la sentencia que debe pronunciar en un caso en que no puede comprobarse la verdad de una afirmación de hecho importante" 66 , la decisión judicial entonces afectará a aquella parte que tenía la carga de probar los hechos y que no realizó la activi$\mathrm{dad}^{67}$, ya que los sistemas jurídicos aun en casos de incertidumbre jurídica y epistemológica no admiten el non liquet ${ }^{68}$. En nuestro sistema esto se fundamentaría constitucionalmente en el principio de inexcusabilidad -artículo 76 inciso $2 \mathrm{CPR}-{ }^{69}$, por tanto la norma sobre la carga de la prueba, aunque resulta paradójico es una regla de juicio, que opera como consecuencia de la "falta de prueba"70.

La institución de la carga de la prueba también sería plenamente coherente con un sistema de libre apreciación de la prueba -sana crítica- y con entregarle poderes al juez; al

\footnotetext{
${ }^{64}$ ROSENBERG, Leo, op. cit. (n. 62), p. 55.

${ }^{65}$ BARCfa LeHMANN, Rodrigo. Lecciones de Derecho Civil Chileno. De la teoría de las obligaciones. Santiago: Editorial Jurídica de Chile, 2008, p. 211.

66 ROSENBERG, Leo, op. cit. (n. 62), p. 2.

${ }^{67}$ Esta es una de las características de la carga de la prueba en oposición a un deber de prueba, si las partes no contribuyen a confirmar el hecho, el tribunal no deberá utilizarlo a la hora de dictar sentencia. Para lo que sirve que esté o no probado el hecho es para "su propio interés de triunfar". Ibid. La conceptualización como carga hace referencia a que en caso de no aportarse pruebas no existe una sanción, pues no se trata de una obligación. Se ha dicho que: "cuando media obligación, el vínculo se impone para la tutela de un interés ajeno; y cuando hay carga, para la tutela de un interés propio". SENTIS MELENDO, Santiago. Estudios de derecho procesal. Tomo I. Buenos Aires: E.J.E.A., 1967, p. 340.

${ }^{68}$ En rigor, la situación de incertidumbre debería llevar a una situación de non liquet, pero son conocidas las razones por la que los ordenamientos modernos tienden a excluir esa posibilidad. TARUfFo, Michele, La Prueba de... (n. 32). p. 247.

${ }^{69} \mathrm{La}$ misma regla se encuentra también en los artículos $175 \mathrm{n}^{\circ} 5$ del CPC y en el artículo 10 COT. La prohibición del "non liquet" (abstenerse de fallar por falta de solución), es históricamente muy anterior; sobre el particular es ilustrativo TOPASIO, Aldo. "Fundamentos históricos del principio de inexcusabilidad del juez en el devenir jurídico hispánico y chileno", en: Revista Chilena de Derecho vol. 9, N², pp. 185 y ss. Santiago: Pontificia Universidad Católica, 1983, 156:194. pp. 185 y ss.

${ }^{70}$ FAIREN GUILLEN, Víctor. Teoría general del derecho procesal. Ciudad Universitaria: UNAM, 1992, p. 445.
} 
respecto señala Rosenberg que "la carga de la prueba le enseña a hallar la solución cuando la libre apreciación de la prueba no ha dado ningún resultado" -concluyendo que "la carga de la prueba le da lo que la libre apreciación de la prueba le negó"- ${ }^{71}$. En el mismo sentido Joan Picó i Junoy expresa que los que alegar que la potestad oficiosa del juez destruye la actual concepción del onus probandi es equívoco, pues "las reglas de la carga de la prueba operan al momento de dictar sentencia"72; no en la fase de aportar antecedentes salvo cuando para accionar se requiera aportar antecedentes.

\subsection{CRÍTICAS A LA INVERSIÓN PROBATORIA EN EL PROCESO LABORAL DEL ARTÍCULO $493 \mathrm{CT}$}

El procedimiento de tutela ha planteado algunas dudas razonables a partir de su normativa, donde no es necesaria una infracción legal, sino una lesión de algunos derechos fundamentales -señalados taxativamente- "en el ejercicio de las facultades del empleador" -artículo $485 \mathrm{CT}$-, lo que implica que la jurisprudencia tendrá un importante rol interpretativo de la colisión de derechos ${ }^{73}$ que necesariamente se genera en un ámbito de subordinación y dependencia ${ }^{74}$. Respetar los derechos no significa solo no vulnerarlos flagrantemente, sino permitir que ciertos derechos puedan ser ejercidos libremente inclusive en el lugar de trabajo, lo que equivale a reconocer y respetar la "ciudadanía en la empresa". Para esto se introdujo una regla especial para facilitar la prueba: "artículo 493 Cuando de los antecedentes aportados por la parte enunciante resulten indicios suficientes de que se ha producido la vulneración de derechos fundamentales, corresponderá al denunciado explicar los fundamentos de las medidas adoptadas y de su proporcionalidad".

La crítica es expresada sucintamente por el profesor William Thayer, quien ha afirmado que una norma de este tipo ignora la norma clave de nuestro ordenamiento jurídico, a saber el artículo 1698 del CC. "que no puede ser irresponsablemente derogada sin trastroca las bases de nuestro estado de derecho" ${ }^{75}$. Por su parte el profesor Claudio Palavecino, sobre el artículo 493 del CT, reconoce que este no supone invertir el peso de la prueba, pero que "acaso hubiera sido preferible que lo hiciera derechamente, porque bajo el eufemismo de

\footnotetext{
71 "El dominio de la carga de la prueba comienza allí donde termina el dominio de la libre apreciación de la prueba; si el juez atravesó este último sin poder encontrar la solución, la carga de la prueba le da lo que la libre apreciación de la prueba le negó." Así ROSENBERG, Leo, op. cit. (n. 62), p. 57.

72 Picó I JUNOY, Joan. El juez y la prueba... (n. 60), p. 108.

${ }^{73} \mathrm{Ha}$ llamado la atención sobre esto en forma crítica THAYER, William. "El nuevo procedimiento laboral. Proyecto antiguo y ley precipitada", en: Actualidad Jurtdica $\mathrm{N}^{\circ}$ 18, p. 533. Santiago: Universidad del Desarrollo, julio 2008.

${ }^{74}$ Como hemos expuesto, somos partidarios de entregar este tipo de poderes a los jueces y de empezar a confiar en ellos. Ver: Bravo HurTado, Pablo. "Confiar en los Jueces. Reforma procesal civil y cambio cultural en Chile", en: La Semana Jurídica No 375, Santiago, 11 al 24 de junio de 2008, p. 2. El autor-colaborador en la Reforma Procesal Civil-comparte el juicio del profesor Michele Taruffo, quien, en una conferencia en Chile, al ser interrogado sobre las potestades de los jueces y cómo se podría controlarlos, este señaló que lo primero es un cambio de mentalidad que debe comenzar por confiar en los jueces.

75 THAYER, William, op. cit. (n. 73), p. 534. Agrega posteriormente que "Probablemente el legislador ha querido enfatizar la obligación que pesa sobre el empleador de cumplir los requisitos legales para poner término al contrato de trabajo, pero incumbe al juez del asunto, conforme al mérito del proceso y basado en las muy amplias facultades de que goza, ponderar la prueba".
} 
Francisco Javier Jara Bustos / La facilidad probatoria en el procedimiento de tutela laboral...

'carga probatoria dinámica' lo que se esconde es incertidumbre y discrecionalidad judicial. El empleador se va a enterar, recién, al momento de leer la sentencia que 'le tocaba probar' y a esas alturas habrá perdido el pleito" 76 , pues entiende el citado autor que la regla de la carga de la prueba opera en el minuto de juzgamiento.

Identifico aquí las dos objeciones principales de las que me haré cargo en este artículo, cuya respuesta creo es esencial para determinar por qué la norma en comento se ajusta a la Constitución y a un proceso racional y justo: (a) la primera es la planteada acerca de la constitucionalidad de la existencia de esta facilidad probatoria; y (b) la segunda, es la relativa al momento procesal en que esa regla entrará en funcionamiento, es decir, cuando sabrá la parte que le tocará probar.

\subsection{Planteamientos DE LA DOCTRINA NACIONAL RESPECTO A ESTA INSTITUCIÓN}

Hay consenso en que existe una regla especial en la materia ${ }^{77}$, sin embargo los autores tienden a pensar que no se trataría de alteración del onus probandi, sino más bien de un principio de aligeramiento probatorio, que tiene por fundamento la dificultad probatoria que tiene el trabajador de probar que la conducta que alega lesiva puede enmarcarse como atentado a sus derechos fundamentales y no tuvo una motivación legítima; por ejemplo un despido discriminatorio encubierto por la causal de necesidades de la empresa ${ }^{78}$. Para que su acceso a la justicia no sea ilusorio se ha reconocido que deben existir mecanismos que permitan resguardar el equilibrio procesal entre las partes ${ }^{79}$.

Respecto de la naturaleza de esta facilidad probatoria, para Sergio Gamonal se trataría de prueba indiciaria ${ }^{80}$, entendiendo por tal un aligeramiento probatorio del demandante trabajador al demandado empleador, que el autor define como "un estándar probatorio que exige una prueba mínima de la vulneración de un derecho fundamental del trabajador subordinado para que sea el empleador quien deba justificar la licitud de la acción"81, es

\footnotetext{
76 El autor se refiere al tema al menos estas columnas: Procedimiento de tutela laboral “¿El fin justifica los medios?”, en: $L a S e-$ mana Jurídica No 333, Santiago, 26 de marzo al 1 de abril de 2007, p. 2.; "Procedimiento de tutela laboral y debido proceso", en: La Semana Jurídica No 336, Santiago, 11 de abril al 22 de abril de 2007, p. 2.; "La carga de la prueba en el procedimiento de tutela laboral", en: La Semana Jurídica No 380, Santiago, 20 de agosto al 02 de septiembre de 2008, p. 2. La cita es del segundo.

77 Las obras generales sobre el nuevo procedimiento coinciden en que se trata de una regla especial, pero existe en general poco tratamiento detenido sobre el tema. Véase SILVA MONTES, Rodrigo. Manual de procedimiento laboral. Santiago: Editorial Jurídica de Chile, 2009, p. 64 -quien se limita únicamente a señalar el texto de la ley-; OrellanA, Fernando. Comentarios al nuevo proceso laboral $-2^{2}$ edición-. Santiago: Librotecnia 2009, p. 263; WALTER, Rodolfo y LANATA, Gabriela. Régimen legal del nuevo proceso laboral chileno $-6^{\mathrm{a}}$ edición-. Santiago: LegalPublishing, 2009, p. 274.

${ }^{78}$ UGARTE, José Luis. Tutela de derechos fundamentales del trabajador. Santiago: LegalPublishing, 2009, p. 41. GAMONAL, Sergio, op. cit. (n. 18), p. 29.

${ }^{79}$ Para Gamonal su consagración se explica por el reconocimiento que han hecho los sistemas procesales de que el trabajador no cuenta con prueba tan completa que permita eliminar todas las dudas, bastando al tribunal la sola comprobación de la verosimilitud. GAMONAL, Sergio, op. cit. (n. 18), p. 2; UGARTE, José Luis, Tutela de derechos... (n. 78), pp. 42-43; WALTER, Rodolfo y LANATA, Gabriela, op. cit. (n. 77), p. 274. En el mismo sentido va el mensaje presidencial, en: Historia de la Ley No 20.087. Biblioteca del Congreso Nacional. 03 de Enero de 2006. Disponible en www.bcn.cl pp. 25-26.

${ }^{80}$ GAMONAL, Sergio, op. cit. (n. 18), p. 27.

81 Ibid.
} 
decir, será el empleador quien debe acreditar que su conducta se debió a motivos razonables compatibles con su facultades de dirección y organización. Para los profesores Walter y Lanata, también sería solo una inversión aparente de la carga probatoria, pues la regla solo exigiría que se presenten indicios ${ }^{82}$, dejando inalterada la regla general, ya que aún recae en el demandante "el peso de aportar, por lo menos, antecedentes de los cuales se puedan desprender los indicios que permitan al juez considerar que la vulneración se ha producido" 83 , en el mismo sentido se pronuncia José Luis Ugarte, para quien tampoco el denunciante está librado de prueba con la sola alegación de vulneración de derechos fundamentales, sino que debe acreditar la existencia de indicios suficientes ${ }^{84}$.

Para apoyar estas conclusiones puede verse también el mensaje presidencial que habla de una matización de la regla sobre carga de la prueba, pero que en ningún caso exige al empleador la prueba de un hecho negativo ${ }^{85}$, asimismo que durante la tramitación del proyecto de reforma a la justicia laboral en el Congreso, la redacción de la norma siempre habló de indicios $^{86}$. En el mismo sentido se pronuncian dos manuales, uno de cursos de la Academia Judicial, y otro para el examen habilitante para juzgados laborales, que califican la norma del artículo $493 \mathrm{CT}$ como una matización de la regla general sobre carga de la prueba, en casos que existan indicios ${ }^{87}$. Existen algunos artículos que habían calificado la situación de la norma como un ejemplo de "cargas probatorias dinámicas", identificadas con inversión del peso de la prueba; esto puede verse en unas columnas de los profesores Eduardo Caamaño y Claudio Palavecino. El primero caracteriza esta carga como una facilitación, más que una inversión del peso de la prueba, y el segundo reconoce que no se trata de una inversión inmediata que opere ipso iure, sino que deja margen a la incertidumbre y al decisionismo judicial $^{88}$.

\footnotetext{
82 WALTER, Rodolfo y LANATA, Gabriela, op. cit. (n. 77), p. 274.

${ }^{83} \mathrm{Ibid}$, ya que de lo contrario, significaría hacer recaer en el empleador la prueba de un hecho negativo -que no existió la violación-.

${ }^{84}$ UGARTE, José Luis, Tutela de derechos... (n. 78), pp. 43 y ss.

85 Así, "se introduce una norma novedosa en nuestro ordenamiento jurídico, absolutamente imprescindible a la hora de brindar protección en este tipo de figuras, en relación con el onus probandi, que consiste en facilitar o alivianar la prueba al denunciante, cuando de sus alegaciones se desprendan indicios en orden a que se ha producido la vulneración de derechos fundamentales. En este caso, surge la obligación para el denunciado de justificar suficientemente, en forma objetiva y razonable, las medidas adoptadas y su proporcionalidad. Se produce entonces, una matización de la regla general sobre la carga de la prueba, ya que al trabajador le basta con que de sus alegaciones se desprendan "indicios", es decir, señales o evidencias que den cuenta de un hecho oculto -violación de un derecho fundamental--. Es de destacar que en este evento no se exige al empleador la prueba de un hecho negativo -que no violó el derecho fundamental-, sino que pruebe que el acto o conducta empresarial obedeció a una motivación legítima". Historia de la Ley No 20.087, op. cit. (n. 79), pp. 25-26.

${ }^{86}$ Desde el proyecto donde era el artículo 510 , aunque cambio su redacción original, esta variación no fue en lo relativo a los indicios, sino como debía explicarse el empleador. Además se eliminó un inciso segundo acerca de discriminación de acceso al trabajo. Historia de la Ley No 20.087, op. cit. (n. 79), pp. 49, 196, 207, entre otras.

${ }^{87}$ ACADEMLA JUDICIAL. Manual de Juicio del Trabajo. Santiago, 2008, p. 142. Habla derechamente de prueba indiciaria; CoRPORACION ADMINISTRATIVA DEL PODER JUdicial. Manual de Estudio Juzgados de Letras del Trabajo. Santiago, 2007 , p. 113. Es interesante analizar esto no porque sean obras destinadas a difusión científica como los trabajos de los académicos, u obras generales de consulta, sino porque constituyen la base sobre la que se forman y perfeccionan nuestros jueces, por lo que inevitablemente es bueno conocer que dicen.

${ }^{88}$ CAAMAÑo, Eduardo. "El procedimiento de tutela: una innovación en sentido correcto", en: La Semana Jurídica No 335 , Santiago, 9 de abril al 15 de abril de 2007, p. 2. PALAVECINO, Claudio. "La carga de la prueba en el procedimiento de tutela
} 
Francisco Javier Jara Bustos / La facilidad probatoria en el procedimiento de tutela laboral...

Analizaremos ahora criterios comparados y nacionales acerca de facilidad e inversión probatoria para analizar si estamos en presencia de una norma desproporcionada.

\subsection{CRITERIOS COMPARADOS SOBRE FACILIDAD E INVERSIÓN PROBATORIA}

Existe una tendencia en derecho comparado a que, atendidas ciertas circunstancias, se establezcan diversos mecanismos de inversión probatoria, entendiendo por tal el "fenómeno de alteración de las reglas de distribución de la carga de la prueba a favor de un sujeto distinto del que normalmente vendría gravado con dicha carga" ${ }^{29}$. Estas instituciones, de facilidad probatoria, se manifiestan en permitir en determinados casos el acceso en mayor o menor medida a los medios probatorios de la contraparte y de terceros siempre que no existan motivos justificados para negarse. Podemos ver ejemplos en la Unión Europea, que decididamente está encaminando su modelo procesal civil a uno donde la verdad y la buena fe procesales tienen un papel importante, así se puede ver la directiva 2004/48/CE del Parlamento Europeo sobre propiedad intelectual se ha establecido en su artículo 6.1 que la parte que tiene en su poder cierta prueba podrá ser requerida para que la presente, con la sola excepción de los datos confidenciales ${ }^{90}$, en la misma dirección apuntan los criterios internacionales; por ejemplo, los parámetros aprobados en Principles of Transnacional Civil Procedu$r e$ de Unidroit y el American Law Institute de 2004, prevén el deber de partes y terceros de garantizarse el acceso a todos los medios de prueba relevantes ${ }^{91}$.

En el Derecho alemán existe indiscutiblemente y en forma esencial una rígida estructura normativa fija para la carga probatoria, y la doctrina mayoritaria ha rechazado aquellas posturas doctrinarias que buscan establecer deberes de esclarecimiento a aquellas partes que ordinariamente no soporten esta carga ${ }^{92}$. Con todo igualmente se reconoce en determinadas áreas, en virtud del desarrollo jurisprudencial una adaptación de la regla permitiendo otra distribución de los riesgos y la carga de la prueba ${ }^{93}$. El reconocimiento de estas adaptaciones jurisprudenciales así como algunos deberes de cooperación en esos casos, se ha fundado en la existencia de ciertas posiciones procesales privilegiadas de las partes. Estos deberes en el derecho germano se expresan principalmente "-en casos de comprensible desconocimiento de la parte que tiene la carga de la alegación- se inclina en el proceso a transferir a la contraparte un deber de aclaración en relación a los hechos que sustancialmente lo requieran y

\footnotetext{
laboral", en: La Semana Juridica № 380, Santiago, 20 de agosto al 2 de septiembre de 2008, p. 2. Definiremos carga probatoria dinámica en la sección 3.4.

${ }^{89}$ RAMOS MÉNDEZ, Francisco. Derecho procesal civil. Tomo I. Barcelona: JM Bosch, 1990, p. 541.

90 Directiva 2004/48/CE del Parlamento Europeo de 29 de abril de 2004. Sobre esto STUURNER, Rolf. "La obtención de información probatoria en el proceso civil", en: Revista de Derecho vol. 30 Nol, pp. 255 y ss. Valparaíso: Pontificia Universidad Católica de Valparaíso, junio 2008.

91 STÜRNER, Rolf. "La obtención... (n. 90), p. 255. (Como el discovery).

92 Perez Ragone, Álvaro; Ortiz Pradillo, Juan Carlos; Pruttring, Hans y De Falco, Sandra. Código Procesal Civil alemán (ZPO). Traducción con estudio introductorio. Montevideo: Fundación Konrad-Adenauer, 2006, pp. 60 y ss. La sección citada fue elaborada por el profesor Prüting.

93 Este desarrollo jurisprudencial existe "especialmente en el ámbito de derecho de daños, responsabilidad profesional, responsabilidad por productos elaborados, responsabilidad médica y responsabilidad por dańos al medio ambiente". Ibid.
} 
sea de plausible conocimiento" 94 . La posición doctrinal minoritaria es la del profesor Rolf Stürner, que en comparación a estándares europeos considera estas medidas insuficientes ${ }^{95}$.

En el Derecho español una interpretación de las garantías fundamentales de los artículos 14 (que establece la igualdad ante la ley) y 24 ( $\mathrm{N}^{\circ}$ s 1 y 2) de la Constitución Española (CE), referidos a los derechos que integran el debido proceso, permite establecer algunos deberes de colaboración mínimos.

En cuanto a la decidida inversión de la carga probatoria surge la doctrina de las "cargas probatorias dinámicas". Para J. Peyrano:

"La llamada doctrina de las cargas probatorias dinámicas puede y debe ser utilizada por los estrados judiciales en determinadas situaciones en las cuales no funcionan adecuada y valiosamente las previsiones legales que, como norma, reparten los esfuerzos probatorios. La misma importa un desplazamiento del onus probandi, según fueren las circunstancias del caso, en cuyo mérito aquel puede recaer, verbigracia, en cabeza de quien está en mejores condiciones técnicas, profesionales o fácticas para producirlas, más allá del emplazamiento como actor o demandado o de tratarse de hechos constitutivos, impeditivos, modificativos o extintivos" 96 .

Sin embargo para el autor citado no se trata aquí de establecer un nuevo dogma, entendiendo por tal otra "regla rígida de distribución de la carga de la prueba que concurra en pie de igualdad con los parámetros legales regulados", sino de formular un correctivo para las situaciones donde la regla de la carga de la prueba elaborada para casos "normales y corrientes" sea insuficiente ${ }^{97}$.

Si bien en Argentina el desarrollo de la institución ha sido principalmente jurisprudencial, ha existido consagración legislativa, tanto dentro de Argentina ${ }^{98}$ como fuera de

\footnotetext{
94 Ibid.

95 STÜrner, Rolf. “La obtención... (n. 90), pp. 244 y ss. Para este autor existe temor a establecer un modelo como el del discovery norteamericano. La doctrina mayoritaria y la jurisprudencia han rechazado su tesis que señala que de lege lata es posible establecer estos deberes amplios de colaboración según una lectura de determinadas disposiciones del Código Procesal Civil alemán.

96 PEYRANO, Jorge. "Nuevos lineamientos de las cargas probatorias dinámicas", en: VV.AA. Cargas probatorias dinámicas. Buenos Aires: Rubinzal-Culzoni, 2008, pp. 19-20. La descripción fue acuñada en las Quintas Jornadas Bonaerenses de Derecho Civil, Comercial, Procesal e Informático, celebradas en Junín en 1992, donde la Comisión de Derecho Procesal formuló dicha descripción. Por su parte Roberto Berizonce las define como "la imposición de la carga de aportación a la parte que, según las circunstancias del caso y la relación o situación jurídica base del conflicto, se encuentre en condiciones técnicas, profesionales o fácticas para suministrarla, con prescindencia de la calidad de actor o demandado en el proceso". Citado por PICO I JUNOY, Joan. El principio de la buena fe procesal. Barcelona: J.M. Bosch Editor, 2003, pp. 155-156.

97 PEYRANO, Jorge, op. cit. (n. 96), p. 24.

98 En el Código Procesal Civil y Comercial de la provincia de Corrientes y en el de La Pampa.
} 
Francisco Javier Jara Bustos / La facilidad probatoria en el procedimiento de tutela laboral...

ella, por ejemplo en el artículo 217 No $7^{99}$ de la Ley de Enjuiciamiento Civil española ${ }^{100}$. La diferencia de este tipo de cargas probatorias con las de facilidad probatoria -artículo 493 CT - a nuestro entender, radica en que esa necesariamente requiere de indicios y la carga dinámica simplemente considerar la facilidad y disponibilidad probatoria.

\subsubsection{La genealogía de la norma del 493 CT en el derecho español}

A propósito de esto veremos otras normas procesales del derecho español y cómo se relacionan con la regla en comento. El artículo 217 LEC dentro de sus reglas sobre carga de la prueba también reconoce expresamente la posibilidad de existencia de normas o criterios de inversión de la carga de la prueba (así en el $\mathrm{N}^{\circ}$ 6). La regla del $217 \mathrm{~N}^{\circ} 5$ consagra una regla sobre facilidad probatoria en casos de discriminación muy similar al artículo $493 \mathrm{CT}$.

En la Ley de Procedimiento Laboral (LPL) también podemos nombrar los artículos 96 -que alude a discriminación en razón de sexo en el procedimiento ordinario- y $179 \mathrm{~N}^{\circ}$ 2 , que se ubica en el procedimiento de tutela de la libertad sindical y demás derechos fundamentales" ${ }^{101}$. Así: "artículo 179. 2. En el acto del juicio, una vez constatada la concurrencia de indicios de que se ha producido violación de la libertad sindical, corresponderá al demandado la aportación de una justificación objetiva y razonable, suficientemente probada, de las medidas adoptadas y de su proporcionalidad".

El procedimiento de tutela de la libertad sindical tiene tramitación preferente y sumariedad. Dentro de las medidas para proteger los derechos fundamentales del denunciante se han establecido reglas especiales de carga de la prueba. Autores como Montero Aroca, han señalado respecto de la interpretación de esa norma, que para aplicar esta norma "No cabe admitir que la mera alegación" sino que "el actor precisa probar uno o varios indicios -hechos indiciarios- de los que no llegue a poder presumirse de modo completo que existe la violación, pero de los que sí pueda deducirse la probabilidad de su existencia"102. Esta inversión probatoria se traduce como una exigencia al demandado de probar (i) que ese acto adoptado por él posee una justificación objetiva y razonable de manera que se hubiese manifestado ante cualquier contingencia y (ii) que mantenga proporcionalidad con su origen. De no

${ }^{99}$ Artículo 217. Carga de la prueba.

5. De acuerdo con las leyes procesales, en aquellos procedimientos en los que las alegaciones de la parte actora se fundamenten en actuaciones discriminatorias por razón del sexo, corresponderá al demandado probar la ausencia de discriminación en las medidas adoptadas $y$ de su proporcionalidad.

6. Las normas contenidas en los apartados precedentes se aplicarán siempre que una disposición legal expresa no distribuya con criterios especiales la carga de probar los hechos relevantes.

7. Para la aplicación de lo dispuesto en los apartados anteriores de este artículo el tribunal deberá tener presente la disponibilidad y facilidad probatoria que corresponde a cada una de las partes del litigio.

100 PEYRANo, Marcos L. "La teoría de las "cargas probatorias dinámicas" en la flamante ley de enjuiciamiento civil española (Ley 1/2000)", en: VV.AA. Cargas probatorias dinámicas. Buenos Aires: Rubinzal-Culzoni, 2008, p. 191. Debemos hacer la prevención de que debido a las reformas legales que ha tenido la LEC, lo que era el $N^{\circ} 6$ del artículo 217 -en la versión original del cuerpo legal- es hoy el $\mathrm{N}^{\circ} 7$.

${ }^{101}$ Aunque el artículo habla solamente de la libertad sindical, de acuerdo al artículo $181 \mathrm{LPL}$ otros derechos fundamentales y libertades públicas se sustancian de acuerdo al mismo procedimiento.

102 MonTERO AROCA, Juan. Introducción al proceso laboral. Madrid: Marcial Pons, 2000, p. 274. 
probar esto puede sufrir consecuencias a través de esta regla de la carga de la prueba, como por ejemplo que se dé por probado el hecho. En el mismo sentido citamos a Baz Tejedor de que esos indicios deben ser menos que pruebas, pero permitir al menos revelar o hacer plausible que hubo una lesión ${ }^{103}$.

Los derechos fundamentales del denunciado también se encuentran resguardados, puesto que aun cuando se le impone a este actor una "auténtica carga probatoria y no de un intento de negar la vulneración de derechos fundamentales" ${ }^{104}$, esta exigencia jamás implicará la prueba de hechos negativos para el empleador de acuerdo al Tribunal Constitucional ${ }^{105}$. Respetándose esta interpretación que exige al trabajador al menos presentar los indicios y al empleador defenderse se entiende que quedan resguardadas las garantías de tutela judicial efectiva, derecho al debido proceso, a la defensa garantizados en la Constitución española.

\subsection{CRITERIOS NACIONALES SOBRE MODIFICACIÓN DE LAS REGLAS PROBATORIAS}

En el derecho chileno en la misma línea del derecho comparado, han sido reconocidas algunas facilidades probatorias en atención a la desigualdad que podría existir entre las partes en determinadas situaciones.

Por ejemplo, en temas laborales encontramos el caso del acoso sexual, donde es el empleador quien está obligado a rendir prueba (Ley $\mathrm{N}^{\circ}$ 20.005). Se establece así facilidad de prueba para la parte presuntamente afectada, por la gravedad de este tipo de atentados. En opinión de los profesores Luis Lizama y José Luis Ugarte, esta medida se establece porque se trata de un "ilícito constitucional pluriofensivo", ya que los actos lesionan diversos derechos de rango constitucional: derecho a la intimidad, a la no discriminación y a la integridad física ${ }^{106}$.

Pero el reconocimiento de variaciones a la regla de la carga de la prueba del artículo 1698 CC no solo es un invento del "laboralismo pro trabajador", ni del "procesalismo más autoritario". En materia civil existen discusiones al respecto en materia de presunciones de culpa, tanto por hecho propio como por hechos del dependiente. Al respecto Enrique Barros explica que las reglas de presunción de culpa, tanto por hecho ajeno como por hecho propio surgen porque en determinados casos la naturaleza de la situación puede ser indicio prima facie de culpa, donde aplicar la regla general da lugar a una prueba diabólica ${ }^{107}$.

\footnotetext{
103 Exigir que se pruebe la lesión "nos situaría fuera del esquema de distribución de cargas probatorias al que responde la denominada prueba indiciaria en el proceso laboral. Muy al contrario el trabajador cumplirá con su carga probatoria con la aportación de hechos a partir de los cuales surja razonablemente un panorama indicativo de la posible restricción en el derecho fundamental". BAZ TEJEDOR, José Antonio. La tutela judicial de los derechos fundamentales en el proceso de trabajo. Valladolid: Editorial Lex Nova S.A., 2006, p. 214.

${ }^{104}$ Sentencia Tribunal Constitucional, $101 / 2000$ de 10 de abril. Sala Segunda.

105 "No se trata de situar al empresario ante la prueba diabblica de un hecho negativo, como es la inexistencia de un móvil lesivo de derechos fundamentales, pero sí debe asumir en estos supuestos, la carga de probar, sin que resulte suficiente el intentarlo, que su actuación tiene causas reales, absolutamente extrañas a la pretendida vulneración de derechos fundamentales, así como que aquellas tuvieron entidad suficiente para adoptar la decisión, único medio para destruir la apariencia lesiva creada por los indicios". Sentencia Tribunal Constitucional $87 / 1998$ de 21 de abril. Sala Primera -El destacado es nuestro-.

${ }^{106}$ Así LiZAMA, Luis y UGARTE, José Luis. Nueva Ley de Acoso Sexual. Santiago: LexisNexis, 2005, p. 5.

107 BARRos, Enrique. Tratado de Responsabilidad Extracontractual. Santiago: Editorial Jurídica de Chile, 2007, pp. 149 y ss. y pp. 180 y ss.
} 
Aplicando la máxima res ipsa loquitur-dejad que las cosas hablen por sí mismas- se expresa la condición más general de esa presunción, que la experiencia enseña que en ciertos casos el daño puede ser atribuido a la negligencia de un hecho que escapa al cuidado del agente $^{108}$. En estos casos, la presunción constituiría una prueba en principio, que "alteraría el peso de la prueba mientras el demandado no muestre una explicación más razonable acerca de cómo pudo ocurrir el accidente por una causa distinta a la propia negligencia" 109 . Esto significa que si el demandado muestra una explicación razonable, le corresponderá al demandante en ese momento probar de acuerdo a las reglas generales.

Respecto de la crítica por la vaguedad del concepto de indicios, pensamos que este no es el lugar para tratar en profundidad el tema. Sin embargo, podemos decir que en su libro sobre el procedimiento de tutela el profesor Gamonal señala una serie de criterios, basándose en trabajos de doctrina que abordan la temática de estándares de prueba, que podrán servir como criterios orientadores ${ }^{10}$. Del mismo modo puede ser útil revisar algunos textos españoles, toda vez que nuestra normativa de tutela laboral está basado en su "proceso de tutela de la libertad sindical y demás derechos fundamentales"111. En todo caso su comprensión dependerá fundamentalmente de nuestros jueces laborales, y del alcance que en la praxis adquiera el concepto, o eventualmente de una futura unificación de jurisprudencia -artículo $483 \mathrm{CT}$-.

\subsection{UNA (CUESTIONABLE) OBJECIÓN A LAS MODIFICACIONES A LA CARGA PROBATORIA}

Ahora bien, aun cuando en derecho comparado casos facilidad probatoria pueden fundarse en los deberes de buena fe procesal, e instituciones como las cargas probatorias dinámicas pueden fundarse en correctivos para lograr un mejor acceso a la justicia, no se nos escapa que se ha objetado por parte del "garantismo" que instituciones como estas pugnan con la presunción de inocencia. Sin embargo, a esto hay que hacer dos aclaraciones. En primer lugar, es claro que una institución como esta no podría usarse en materia penal para vulnerar el principio de prohibición de autoincriminación forzosa y la presunción de inocencia, consagrada en diversos cuerpos normativos, como el artículo 11 de la Declaración

\footnotetext{
108 Ibid. En el derecho comparado ha habido un desarrollo similar en responsabilidad por productor defectuosos.

109 Ibid. p. 157.

110 GamONal, Sergio, op. cit. (n. 18), p. 28. Como los de Larry Laudan, Michele Taruffo y Marina Gascón. Asimismo pueden consultarse las obras citadas de José Luis Ugarte, y Rodolfo Walter y Gabriela Lanata. Probablemente recomendaría leer con cuidado el Manual de la Academia Judicial por estimar que al hablar la norma de indicios -en plural-se estima que deben ser múltiples criterio por demás arbitrario, pudiendo ser solo un indicio atendida su gravedad. ACADEMIA JUDICIAL, op. cit. (n. 87), p. 142. También véase TARUfFo, Michele, La Prueba de... (n. 32), pp. 508-513, para quien indicios puede perfectamente referirse a un indicio, aunque como se considera la verosimilitud idealmente deben ser circunstancias precisas y concordantes. Para una defensa de la prueba por indicios y su fuerza probatoria, véase GASCON ABELLAN, Marina, op. cit. (n. 35), pp. 160 y ss. Desde la perspectiva de los autores nacionales que lo asimilan a prueba indiciaria o por presunciones -criterio discutibletambién es posible sostener esta conclusión, puesto que la norma supletoria sería la del artículo $427 \mathrm{CPC}$, que señala que una sola presunción puede constituir plena prueba. Con la salvedad de que la lógica de la plena prueba tasada es extraña al nuevo sistema procesal.

111 Como vimos, en el sistema español se acepta que un solo indicio puede dar lugar a la aplicación de la norma del 179 No 2 LPL.
} 
Universal de Derechos Humanos, el artículo 8 inciso 2 de la Convención Americana sobre Derecho Humanos, el artículo 19 No 3 CPR, y el artículo 4 del CPP. Por esta razón su uso solo se ha desarrollado en el ámbito procesal civil, y ante supuestos donde las circunstancias lo han justificado, tomando en consideración la posición de las partes, los deberes de colaboración que pueden establecerse para no menoscabar las facultades probatorias de unos u otros. En segundo lugar, resulta problemático el que un sector de la doctrina hable de presunción de inocencia en sede civil, pues es un principio penal ${ }^{12}$, por lo que ni la facilidad probatoria, ni aun la inversión del onus probandi en materias civiles podría afectar este principio.

Hasta aquí hemos visto que en el derecho comparado así como en el nacional son plenamente justificables ciertas facilidades de prueba o modificaciones de la carga de probar. Esto es concordante con el establecimiento de deberes de buena fe -de distinta intensidad-, de reconocer que en ciertas circunstancias fácticas o la entidad de los derechos protegidos la regla tradicional sobre distribución del onus probandi, en la medida que se asegure adecuadamente un debido proceso que comprenda bilateralidad, derecho a producir pruebas y derecho a defensa.

Ahora bien, sin perjuicio de que creemos haber señalado suficientes razones de por qué sería plenamente admisible la inversión probatoria del $493 \mathrm{CT}$, reconocemos que la preocupación por esta institución de los profesores Thayer y Palavecino es justificada, pues sin duda importa la recepción de instituciones procesales poco conocidas en nuestra legislación, alterando la concepción procesal clásica ${ }^{113}$.

\section{TRAMITACIÓN PROCESAL Y DERECHO A LA DEFENSA}

La segunda objeción que propone el profesor Palavecino es respecto del momento en que "el tribunal deberá ponderar y declarar la suficiencia o insuficiencia de aquellos indicios"114. El autor en cuestión señala que la ley nada dice sobre el particular, ni tampoco sobre el deber del juez de advertir al demandado con la debida antelación que debe aportar la prueba que justifique los fundamentos de las medidas adoptadas y su proporcionalidad, llegando a imaginar que podría darse el caso de que en el momento de la sentencia se entere que debía presentar los antecedentes que exige el artículo $493 \mathrm{CT}$, y por lo tanto pierda irremediablemente el pleito. Se daría en este caso una situación similar a la del absurdo juicio llevado por la Reina de Corazones en la clásica obra de Lewis Carroll, donde la regla sería dictar la sentencia primero, para después traer las pruebas, ante lo que Alicia le reclama

\footnotetext{
112 Aunque podría extenderse a la vertiente sancionadora del derecho administrativo, ya que también es una manifestación del ius puniendi. Este principio se ve por ejemplo en el artículo $340 \mathrm{CPP}$ que impide condenar a una persona con el solo mérito de su declaración, regla inexistente en el ámbito procesal civil. En este sentido se ha expresado también BordaLf, Andrés, op. cit. (n. 60), pp. 272-275. Respondiendo a críticas del garantismo.

113 Señala Adolfo Alvarado Velloso que dicha doctrina "es exótica y divorciada de la realidad de la vida tribunalicia", pues "¿cómo puede serle exigido (a alguien) que colabore solidariamente con su enemigo y, que si no lo hace, se considere caído en inconducta procesal? Ver su: La prueba judicial. Reflexiones críticas sobre la confirmación procesal. Rosario: Juris, 2007, pp. 58 y ss. ${ }^{114}$ Así ha expresado el autor en algunos artículos sobre carga de la prueba. Ver nota 76.
} 
lo absurdo de la situación ${ }^{115}$. Para evitar este sinsentido, creemos que en caso de darse una situación como la que se plantea el profesor, procedería el recurso de nulidad -artículo 477 CT-, ya que este procede: "cuando en la tramitación del procedimiento o en la dictación de la sentencia definitiva se hubieren infringido sustancialmente derechos o garantías constitucionales (...)". En caso de la obligación probatoria que es recién informada en la sentencia se habría vulnerado gravemente el derecho a la prueba, que como conceptualizamos, comprende "la garantía de la participación de los interesados en la formación del juicio jurisdiccional" 116 , además de poder presentar pruebas y el saber oportunamente quién deberá presentarlas. En definitiva importaría una vulneración al debido proceso. Esta conclusión la apoyamos en los siguientes argumentos:

(i) En primer lugar señalamos un argumento sistemático, basado en el hecho de que el procedimiento de tutela se remite a la tramitación del procedimiento de aplicación general -artículo $491 \mathrm{CT}$-, que cuenta con dos audiencias ${ }^{117}$. Como sabemos la finalidad de la audiencia preparatoria es triple y comprende: "establecer los hechos que son parte de la controversia que deberá ser decidida por el juez; procurar la solución de la controversia por el acuerdo de las partes a través de la conciliación, y establecer las pruebas que rendirán las partes en la audiencia de juicio" 118 .

Si el sistema se estructura sobre la base de una audiencia preparatoria que fija la controversia y establece las pruebas que se rendirán en la audiencia de juicio, y que la audiencia de juicio es aquella donde debe producirse la prueba, debemos pensar la institución del artículo 493 CT debe regirse por la misma lógica interna del procedimiento laboral. Así podemos pensar que si el artículo citado es un antecedente para la determinación de los hechos controvertidos en el juicio laboral, es claro pensar que este debate -el de la determinación de los hechos controvertidos- debe plantearse en la audiencia de preparación, y establecido esto, corresponderá en audiencia de juicio al empleador "explicar los fundamentos de las medidas adoptadas y su proporcionalidad".

En el derecho español no se da esta problemática en la Ley de Procedimiento Laboral, ni en el procedimiento ordinario ni en el de tutela de la libertad sindical, puesto que solamente existe una audiencia de conciliación y juicio por la concentración de este tipo de procedimientos. De este modo la constatación de los indicios solo puede realizarse en el propio acto de juicio, sin perjuicio de otras reglas especiales que pueda haber.

\footnotetext{
115 En verdad la frase de la Reina "Sentence first - verdict afterwards" significa "la sentencia primero, el veredicto después." Lo que ocurre es que en el sistema angloamericano, es el jurado el que debe emitir el veredicto sobre la culpabilidad (guilty/ not guilty), que es una cuestión de hecho. El juez posteriormente en la sentencia debe aplicar el derecho. Se cambió la palabra veredicto por pruebas, para hacer entendible la traducción, pues en realidad en la historia original Alicia cuestiona a la Reina de Corazones por ordenar sentenciar a la Jota de Corazones sin haber oído el veredicto. Capítulo XII del libro Alicia en el País de las Maravillas. [Disponible en inglés en www.gutemberg.org ].

116 CAROCCA, Alex. "La defensa en el nuevo proceso penal", en: Revista Chilena de Derecho vol. $29 \mathrm{~N}^{\circ} 2$, pp. 283-301. Santiago: Pontificia Universidad Católica de Chile, 2002. En particular en lo referido al derecho a la prueba.

117 Esto nos parece de fundamental importancia para la comprensión que debe hacerse de la norma del artículo $493 \mathrm{CT}$, pues si bien podría haber casos de procedimientos que comiencen con resoluciones judiciales e incluso sentencias (como el monitorio laboral chileno), por su especial estructura, esta lógica es ajena a la del procedimiento de aplicación general laboral y en general a los procesos estructurados en dos audiencias.

118 ACADEMIA JUDICIAL, op. cit. (n. 87), p. 90.
} 
(ii) Un segundo argumento dice relación con la naturaleza de los indicios. Hay argumentos para sostener que los indicios no son prueba, por lo que estos podrían presentarse en la audiencia preparatoria. Nótese como en ningún momento al establecer el requisito de presentar indicios se habla de prueba, pues la prueba -de acuerdo a la regla general en las nuevas leyes procesales- solo se rinde en la etapa de juicio ${ }^{119}$, salvo hipótesis de pruebas adelantadas, reconocidas por la ley laboral, lo que con menor razón obstará al derecho a defensa. Los autores nacionales -como mencionamos en el apartado correspondiente- reconocen que los indicios son algo distinto a la prueba, en doctrina comparada se han realizado también planteamientos más elaborados al respecto. Michele Taruffo se refiere a la existencia de presunciones con el "hecho básico en blanco" ${ }^{120}$, como una herramienta que se utiliza para presunciones en casos de discriminación laboral ${ }^{121}$. Con todo -admite el autor- "a partir de esas circunstancias no es posible derivar valoraciones de probabilidad acerca de la verdad del acto discriminatorio en el caso concreto, aunque solo sea porque aquellas circunstancias se refieren a conductas "generales" del empleador y a las políticas de gestión de la empresa, no al supuesto particular invocado"122, es decir las circunstancias presentadas o alegadas por el trabajador no son en ningún sentido confirmación, ni se basan en la probabilidad de su ocurrencia, sino que dicen relación con un análisis de su verosimilitud. Ese análisis deberá ser hecho por el juez, y deberá justificar su decisión.

(iii) En el mismo sentido del argumento anterior -salvo ciertas pruebas adelantadasnuestro derecho procesal laboral no admite ofrecer pruebas fuera de la audiencia preparatoria $^{123}$, por lo que con menor razón se podría solicitar que el empleador en la audiencia de juicio reciba la carga de explicar el fundamento de las medidas adoptadas. El explicar los fundamentos de las medidas tomadas y de su proporcionalidad si constituye una carga de probar para el empleador que su actuación obedeció a un fin legítimo en el marco de su potestad normativa, que no tuvo por fin vulnerar derechos fundamentales, y que es una medida proporcional atendidas las circunstancias del caso.

(iv) Desde una perspectiva epistemológica que considera como una condición de justicia el establecimiento de la verdad del material fáctico se hace indispensable la posibilidad de contradicción de las afirmaciones como una garantía. El establecer poderes al juez que permiten valorar racionalmente las pruebas o proponer de oficio medidas probatorias es un contrasentido si se le permite decidir que hay indicios solo al momento de dictar sentencia cuando ni los justiciables ni el propio magistrado pueden producir pruebas tendientes a la comprobación o refutación de estos indicios -artículos 429 y $453 \mathrm{~N}^{\circ} 9 \mathrm{CT}$ -

\footnotetext{
119 Esa es la regla general en los procedimientos estructurados en dos audiencias, en este sentido CAROCCA, Alex, "La defensa... (n. 116), p. 287. En general todos los autores son de la misma opinión y la ley es bastante clara. Incluso a la audiencia de juicio se le llama regularmente audiencia o fase de prueba. MATURANA, Cristián, op. cit. (n. 7), p. 18. NỨ̃EZ OJEDA, Raúl. “Crónica sobre la Reforma... (n. 7), p. 689. En materia laboral se consagra también que la audiencia de juicio "está destinada a recibir las pruebas", así WALTER, Rodolfo y LANATA, Gabriela, op. cit. (n. 77), p. 185.

120 TARUfFo, Michele, La Prueba de... (n. 32), pp. 510-511.

121 Ibid.

122 Ibid.

${ }^{123}$ El CPP y la LTF admiten la llamada "Prueba No Solicitada Oportunamente", no así el CT ni el PCPC.
} 
Francisco Javier Jara Bustos / La facilidad probatoria en el procedimiento de tutela laboral...

(v) Esta conclusión también encuentra asidero desde la perspectiva del derecho a la defensa, de los deberes de colaboración y buena fe procesal que hemos enunciado ${ }^{124}$, toda vez que es la única lectura de la norma que permitiría a las partes poder conocer cuando habrían indicios suficientes, y poder producir pruebas atingentes a establecer los fundamentos de la proporcionalidad de estas medidas tomadas para no perder el juicio sin poder probar, en el caso del denunciado, o bien para producir pruebas sobre la lesión en el caso del denunciante que no pudo establecer indicios. En caso contrario sería una situación mucho peor que la del artículo 159 CPC.

\subsection{LA RESPUESTA DE LOS AUTORES NACIONALES SOBRE ESTA SITUACIÓN}

Revisaremos -y cuando corresponda rebatiremos- los argumentos que se han dado por la doctrina en nuestro país sobre el momento donde se aplica el artículo 493 del CT.

(vi) En general los pocos autores que se han pronunciado sobre el particular son de la idea de que la norma del artículo 493 CT recibe su aplicación a la hora de dictar sentencia y no en la audiencia preparatoria. Aquí concuerdan los profesores Claudio Palavecino y José Luis Ugarte. El primero argumenta que la norma del artículo $493 \mathrm{CT}$, al igual que la contenida en el artículo $1698 \mathrm{CC}$, es una regla de juzgamiento que opera una vez agotada la posibilidad de rendir prueba y que no existe disposición legal alguna que autorice al juez a anticipar su efecto ${ }^{125}$. Esta visión obstaculiza una comprensión racional del sistema, toda vez que la regla del 493 CT daría pie a una institución similar a las medidas para mejor resolver, que no podían ser discutidas por las partes, lo que volvería ilusorias muchas de las garantías como el derecho a la defensa, pues sería imposible discutir en juicio dicha prueba, tampoco se podría ejercer el derecho a producir prueba, pues el empleador no sabrá que tiene que hacerlo. Si esto fuera así, el mandato constitucional que busca asegurar el derecho fundamental a un proceso racional y justo tendría su excepción paradójicamente en el procedimiento que busca proteger derechos fundamentales.

Por su parte el profesor Ugarte, se basa en la norma del artículo $8 \mathrm{CC}$ sobre presunción de conocimiento de la ley, que señala que el empleador debería estar en conocimiento de que en virtud de la norma del artículo $493 \mathrm{CT}$ en aquellos casos en que el trabajador presente indicios suficientes, deberá probar, so pena de que la aplicación de la inversión de la carga de la prueba lo afecte ${ }^{126}$. Pensamos que esta argumentación está equivocada, porque obliga al empleador a ponerse en el peor de los supuestos, ya que si solo a la hora de la sentencia va a conocer si se debe probar, cualquier empleador razonable se esmerará en producir todas las pruebas po-

\footnotetext{
${ }^{124}$ Estamos de acuerdo la idea de que "si bien el proceso civil es una disputa de intereses, una lucha entre partes, esta debe ser leal y guiada por la verdad, tanto en cuanto al fondo o al derecho pretendido como a la forma de llevarlo adelante", si no se está de acuerdo con estas concepciones de una lucha leal -que permiten justificar las cargas probatorias dinámicas- dejaría de tener sentido la idea de exclusión de la prueba ilícita. MASCIOTRA, Mario. La conducta procesal de las partes. Buenos Aires: AdHoc, 2005, p. 137.

${ }^{125} \mathrm{He}$ discutido este argumento con el profesor, y entiendo que se encuentra en preparación de trabajos dogmáticos sobre el tema de la inversión probatoria, pero hasta donde sé no lo ha publicado y tampoco he tenido acceso a los borradores de esos trabajos, por lo que puedo estar simplificando su argumento.

${ }^{126}$ UgARTE, José Luis, Tutela de derechos... (n. 78), p. 46.
} 
sibles para evitar esta situación. Así nos veríamos en la situación absurda donde los empleadores colapsarán los juicios presentando pruebas, que en muchos casos ni siquiera podrán producirse porque no existen. Nótese que ni aún en el caso de ponerse el empleador en el peor de los supuestos y traer toda la prueba que crea pertinente estará asegurado, pues corre el riesgo de que no sea admitida por "no tener relación directa con el asunto sometido a tramitación" o por "no ser necesarias para su resolución” de acuerdo con lo prescrito por el artículo $453 \mathrm{~N}^{\circ} 4 \mathrm{CT}$.

Si el profesor Ugarte -al igual que nosotros- valora el procedimiento de tutela, porque libra al trabajador de presentar pruebas diabólicas por la dificultad que tanto en nuestro derecho, como en el ámbito comparado se reconoce respecto de la posibilidad del actor de obtener pruebas de vulneraciones a derechos fundamentales acaecidas durante la relación laboral ${ }^{127}$, al sostener que esta es una "regla legal de juicio" que por tanto no opera ni en la audiencia preparatoria -etapa de aceprabilidad de prueba- ni en la audiencia de juicio -rendición de prueba-, "debe entenderse conocida por las partes como cualquier otra regla de derecho"128, estaría obligando ahora al denunciado a cargar con la producción de pruebas de descargo casi igualmente imposibles, o incluso de probar hechos negativos. Este autor también pasa por sobre el rol del juez en el proceso, puesto que parece mucho más razonable que sea él quien en la primera audiencia haga la valoración de la verosimilitud de los indicios, con la debida justificación para que en audiencia de juicio el empleador pueda dar explicaciones (como señalamos en el punto ii respecto a la naturaleza de los indicios) y no que el empleador denunciado deba además entrar a suponer si hay indicios; parece que nuestra interpretación es más coherente con los poderes del juez, con el deber de justificación de las resoluciones, la bilateralidad y el derecho a la prueba y a la defensa.

(vii) Respecto de que el juez valore en audiencia preparatoria la verosimilitud, se me ha contestado que la idea de que el juez señale en esa oportunidad procesal que indicios son suficientes constituiría prejuzgar ${ }^{129}$. No nos satisface esta respuesta, pues, en primer lugar, quienes argumentan esto omiten que durante diversos momentos del proceso laboral, los jueces emiten pronunciamientos que no los inhabilitan: (a) En la audiencia preparatoria podemos identificar la conciliación, donde los jueces deben proponer una solución también existe un pronunciamiento sobre la causa por parte de los jueces, que no por eso los inhabilita ${ }^{130}$; (b) En la admisión de las pruebas el juez se debe pronunciar sobre la pertinencia de las pruebas ofrecidas, señalando aquellas que no admitirá sea por causales de ilicitud, por no relacionarse directamente al objeto del juicio ${ }^{131}$; (c) Tampoco sería problemático puesto que el decretar medidas cautelares ni precautorias no se entiende como prejuzgar, sin perjuicio de que requiere valorar ciertos indicios incluso antes de presentada la demanda ${ }^{132}$. Por estos

\footnotetext{
127 Ibid.

128 UGARTE, José Luis. "Tutela laboral de derechos fundamentales y carga de la prueba", en: Revista de Derecho vol. $33 \mathrm{~N}^{\circ} 2$, pp. 222-223. Valparaíso: Pontificia Universidad Católica de Valparaíso, diciembre 2009, 215:228. pp. 222 y 223.

${ }^{129}$ Esta idea también me la ha planteado el profesor Palavecino.

${ }^{130}$ Así de acuerdo al $453 \mathrm{~N}^{\circ} 2 \mathrm{CT}$, y a las reglas supletorias del $182 \mathrm{CPC}$.

131 Artículo 453 No 4 CT.

132 Esto puede realizarse incluso antes de la notificación de la persona contra que se dicten. Las medidas precautorias pueden incluso tener efecto antes de la presentación de la demanda si se acreditan razonables fundamentos y la necesidad del derecho reclamado-Artículo 444 CT-.
} 
Francisco Javier Jara Bustos / La facilidad probatoria en el procedimiento de tutela laboral...

argumentos de lege lata podríamos apoyar nuestra conclusión de que la audiencia preparatoria es un momento idóneo para que el magistrado evalúe si existen indicios, otorgando traslado a ambas partes.

Una segunda razón para no alarmarnos por el prejuzgamiento es que conoce de las dos audiencias un mismo juez - ver el punto siguiente-.

(viii) Los profesores citados parecen olvidar que los procedimientos orales se basan en una gran desformalización y en otorgar poderes de dirección a los jueces, que deben ser interpretados en coherencia con el modelo y con los principios que lo informan, además de los principios del proceso, como el derecho a la prueba, el debido proceso. Las normas que regulan los procesos orales contienen menos disposiciones relativas a la sustanciación del juicio, porque se ha entendido que el excesivo ritualismo de los juicios es una característica negativa que se intenta evitar. Incluso en algunos casos donde no existe ley, es posible que una práctica acorde a los principios permita subsanar el problema. Una muestra destacable del entendimiento del sistema de garantías de los nuevos Juzgados de Letras del Trabajo es que hayan solucionado con la práctica la falta de norma que impide a un mismo juez estar presente en la audiencia preparatoria y en la de juicio de un mismo caso, porque se entiende que el tener al mismo juez en ambas audiencias choca contra lógica de las garantías del sistema, abriendo la puerta, por ejemplo a que un juez presente en ambas audiencias podría contaminarse con pruebas ilícitas de que tomó conocimiento en la audiencia preparatoria.

(ix) Desde el punto de vista de la lógica de las impugnaciones la solución propuesta por los profesores tampoco resulta satisfactoria. Si consideramos que el recurso de nulidad es el único recurso para atacar sentencias definitivas -artículo $477 \mathrm{CT}$, sin considerar el recurso de unificación de jurisprudencia- y se trata de un recurso extraordinario, no parece adecuado que en la práctica vaya a ser el medio ordinario para impugnar aquellos casos en que las partes estimen que se utilizó erróneamente el artículo $493 \mathrm{CT}$, puesto que su uso se da en la sentencia. Pareciera que si la discusión ocurre en audiencia preparatoria, el juez puede escuchar los planteamientos de las partes respecto de las resoluciones, se puede conferir traslado a la contraria, y en caso de desacuerdos la impugnación por regla general se produciría en principio por medio del recurso de reposición laboral, o por otros medios de impugnación. El concebir el recurso extraordinario como recurso ordinario a ser utilizado desnaturalizaría el sistema.

(x) Queremos destacar que existe un autor que se ha pronunciado en el mismo sentido que nosotros respecto del momento procesal donde funciona la norma de inversión probatoria. Así el profesor Fernando Orellana en su libro sobre el nuevo procedimiento laboral señala sobre la norma del 493 CT, que a su juicio "el tribunal deberá señalar en la audiencia preparatoria esta característica al denunciado.", pero lamentablemente el autor no entrega ninguna razón al respecto, por lo que malamente nos servirá su apoyo. No obstante intuimos que el autor ha tenido en mente la afectación de garantías fundamentales ${ }^{133}$.

\footnotetext{
${ }^{133}$ Orellana, Fernando, op. cit. (n. 77), p. 263. Probablemente el autor consideraba esto demasiado obvio, pues las otras posibilidades de interpretación de la norma redundan en la indefensión de una de las partes, o bien, adolecerían de alguno de los problemas que hemos identificado, lo que repugna a nuestras garantías procesales y al sistema procesal.
} 
(xi) El tema en cuestión también ha sido abordado expresamente en el -recientemente publicado- artículo "Las cargas probatorias dinámicas" de Cristina Santibáñez Boric ${ }^{134}$. La autora concluye que además de romper con la igualdad procesal -argumento con el que discrepamos, toda vez que hemos dado buenas razones para sostener que reconocer la disparidad de acceso a ciertos medios probatorios puede justificar reglas diferenciadas-, se trata de una medida que "vulnera el derecho a la debida defensa, en cuanto no se le advierte oportunamente de la posibilidad de que se altere la regla de la carga de la prueba y se vea obligado a acreditar una cuestión diversa a los hechos enunciados en su defensa, en la medida que el juez solo recurrirá a la regla de las cargas dinámicas al momento de dictar sentencia", concordamos con esta segunda conclusión, así como con la.idea de que "resulta imperioso modificar esta norma y establecer una regla clara que ponga término a la incertidumbre procesal para la parte demandada"135.

Por los argumentos antedichos, creemos que la propuesta de interpretación de la norma que hemos enunciado parece ser más correcta. De todos modos, pensamos que esta no es una discusión cerrada, ni que pensar el tema haya sido una actividad en vano. Siempre conviene intentar dilucidar estas cosas por los problemas prácticos e interpretativos que puede generar una institución tan novedosa en nuestro derecho procesal laboral como necesaria ${ }^{136}$. Queremos al respecto citar a Raúl Tavolari a propósito del establecimiento de una norma de inversión probatoria en el Proyecto de Código Procesal Civil -PCPC-. El profesor Tavolari admite ser algo reacio a estas medidas, pero reconoce que es "necesario recoger el principio de facilidad de la prueba e incluso la idea de la inversión de la carga a la sola condición de que, agotado el debate y antes de la proposición y producción de la prueba, el tribunal lo advierta al sujeto sobre cuyos hombros hará descansar esta carga, a fin de evitar sorpresas o arbitrariedades" 137 .

En esta línea, la norma del artículo 265 del PCPC dejaría resuelta la controversia, pues al aprobarse el proyecto la norma pasaría a convertirse en supletoria -artículo 14 PCPC-, lo que permitiría responder estos conflictos interpretativos más pacíficamente. Dice el artículo:

"Artículo 265. Carga de la prueba. Corresponde la carga de probar los fundamentos de hecho contenidos en la norma jurídica a la parte cuya aplicación le beneficie, salvo que una disposición legal expresa distribuya con criterios especiales diferentes la carga de probar los hechos relevantes entre las partes.

\footnotetext{
134 SANTIBAÑEZ BORIC, Cristina. "Las cargas probatorias dinámicas", en: Revista Chilena de Derecho del Trabajo y de la Seguridad Social vol. 1. No 1, pp. 83-92. Santiago: Universidad de Chile, 2010. Reviso este artículo en esta sección, pues tomé conocimiento de la existencia de él solo a comienzos de junio durante el lanzamiento de la Revista Chilena de Derecho del Trabajo, en el marco del "Primer Congreso Nacional Estudiantil de Derecho del Trabajo" realizado en Concepción, lugar donde por primera vez presenté en una ponencia mis ideas sobre el tema".

135 Ibid.

${ }^{136}$ En toda la jurisprudencia que hemos revisado -en los pocos casos donde ha procedido- el artículo 493 CT solo se ha aplicado en la etapa de dictación de sentencia, no obstante falta un análisis más detallado.

137 TAVOLARI, Raúl. "Bases y criterios para el nuevo proceso civil chileno", en: DE la Oliva SaNTOS, Andrés y Palomo Vélez, Diego (coord.). Proceso Civil. Hacia una nueva justicia civil. Santiago: Editorial Jurídica de Chile, 2007, pp. 46-47.
} 
Francisco Javier Jara Bustos / La facilidad probatoria en el procedimiento de tutela laboral...

El tribunal podrá distribuir la carga de la prueba conforme a la disponibilidad y facilidad probatoria que posea cada una de las partes en el litigio, lo que comunicará a la parte con la debida antelación para que ella asuma las consecuencias que le pueda generar la omisión de información de antecedentes probatorios o de rendición de la prueba que disponga en su poder".

\section{CONCLUSIONES}

Para terminar, quisiéramos enunciar brevemente algunas de las conclusiones a las que hemos llegado en el presente estudio:

1) En primer lugar, una adecuada comprensión de la Reforma a la Justicia Laboral no puede entenderse solamente desde la lógica del derecho del trabajo, sino que debe considerar las reflexiones que ha desarrollado la dogmática Procesal Civil y los estudios para la Reforma Procesal Civil. Del mismo modo las reglas de la LPL, la LEC, y la doctrina y jurisprudencia española pueden servirnos muchísimo.

2) El acceso a la justicia es uno de los objetivos que deben guiar a las reformas procesales para lograr decisiones justas. Estas ideas explican la adopción de determinadas formas procesales a favor de otras en lo relativo a los poderes del juez, y a sus facultades para apreciar la prueba.

3) La existencia de un sistema que contempla jueces con un rol de dirección del proceso, con facultades probatorias y de apreciación de la prueba acorde a la sana crítica, no debe entenderse como limitante de los derechos de las partes, sino como reformas encaminadas a lograr un mejor funcionamiento del sistema procesal, respetando estos derechos. Entender este tipo de normas como un signo de autoritarismo revela una importante confusión en materia de filosofía política, pues son compatibles con un estado democrático.

4) Entre las novedades del nuevo procedimiento laboral se encuentra una norma que consagra facilidad probatoria atendidas las especiales circunstancias en que se configuran las vulneraciones de derechos fundamentales durante la relación laboral y su gravedad.

5) Constatamos que buena parte de la literatura nacional dedicada al tema no aborda con la suficiente detención temas de tanta importancia teórica como práctica, limitándose en muchos casos a la exégesis normativa.

6) Respecto a los autores que han tratado la normativa, hemos identificado e intentado responder a dos de las objeciones a la institución que nos parecen más relevantes. La primera es la relativa a su justificación, en vista de que para algunos trastroca la norma de la carga de la prueba, componente fundamental del proceso y del Estado de Derecho. La segunda es la que se refiere a la tramitación que debe dársele a esta norma.

7) Para hacernos cargo de la primera crítica revisamos la carga de la prueba así como los distintos principios relativos a facilidad e inversión probatoria, y cómo estos encuentran cabida en estados con fuertes sistemas democráticos y de protección de derechos, tanto internos como internacionales (el caso Europeo es paradigmático). De lo an- 
terior concluimos que tanto reglas legales, o incluso prácticas jurisprudenciales que modifiquen la carga de la prueba, son a menudo necesarias para no volver ilusoria la justa resolución de los conflictos.

8) Respecto a las objeciones sobre la tramitación, señalamos una serie de argumentos donde defendemos que el momento procesal más adecuado para que se haga efectiva la norma del artículo 493 es la audiencia preparatoria. Atendimos, entre otros, a criterios sistemáticos respecto de los poderes de los jueces, de la configuración del modelo de dos audiencias (que se remite al procedimiento de aplicación general), al tenor de la normal (que habla de indicios y no de prueba), a una adecuación armónica de esta con el sistema de recursos (resultando ilógico que la nulidad se convierta en el medio general para impugnar usos inadecuados del artículo 493 CT), a cómo deben entenderse el rol del juez en relación a los indicios presentados por las partes, entre otras.

9) Creemos que la interpretación de la norma se facilitará enormemente cuando la Reforma Procesal Civil se convierta en Ley de la República, puesto que el proyecto en sus actuales términos contiene una normativa que debería volverse supletoria para interpretar este procedimiento estableciendo obligación de dar aviso a la parte afectada.

10) Finalmente, concluimos que la normativa del artículo 493 CT además de cumplir el estándar mínimo de ajustarse plenamente al debido proceso y a la Constitución, cumple las exigencias que demanda un sistema normativo comprometido con garantizar el acceso a la justicia.

\section{BIBLIOGRAFÍA}

ACADEMIa Judicial. Manual de Juicio del Trabajo. Santiago, 2008.

ALEXY, Robert. Teoria de los Derechos Fundamentales. Madrid: Centro de Estudios Constitucionales, 1993.

ALVARADO, Adolfo. La prueba judicial. Reflexiones críticas sobre la confirmación procesal. Rosario: Juris. 2007.

ANDOLINA, Italo. Cognición"y "Ejecución Forzada" en el Sistema de la Tutela Jurisdiccional. Lima: Communitas, 2008.

ATRIA, Fernando. "Jurisdicción e independencia judicial: el poder judicial como poder nulo", en: Revista de Estudios de la Justicia No 5, pp. 119-141. Santiago: Centro de Estudios de la Justicia, Facultad de Derecho, Universidad de Chile, 2004.

ATRIA, Fernando. "El derecho y la contingencia de lo político", en: DOXA N² 26. Alicante, 2006, pp. 319-345.

BarCfa Lehmann, Rodrigo. Lecciones de Derecho Civil Chileno. De la teoría de las obligaciones. Santiago: Editorial Jurídica de Chile, 2008.

BARROS, Enrique. Tratado de Responsabilidad Extracontractual. Santiago: Editorial Jurídica de Chile, 2007.

BAZ TEJEDOR, José Antonio. La tutela judicial de los derechos fundamentales en el proceso de trabajo. Valladolid: Editorial Lex Nova S.A., 2006.

BORDALf, Andrés. "El debido proceso civil", en: FERrADA BÓRQUEZ, Juan Carlos (Coord.). La constitucionalización del derecho chileno. Santiago: Editorial Jurídica de Chile, 2003, pp. 267-274.

Bravo Hurtado, Pablo. "Confiar en los Jueces. Reforma procesal civil y cambio cultural en Chile", en: $L a S e$ mana Jurídica No 375, Santiago, 11 al 24 de junio de 2008.

CAAMAÑo, Eduardo. "El procedimiento de tutela: una innovación en sentido correcto", en: La Semana Jurídica No 335, Santiago, 9 de abril al 15 de abril de 2007. 
Francisco Javier Jara Bustos / La facilidad probatoria en el procedimiento de tutela laboral...

CAPELLETII, Mauro y GaRTH, Bryant. El acceso a la justicia. La tendencia en el movimiento mundial para hacer efectivos los derechos. México: Fondo de Cultura Económica, 1996.

CAROCCA, Alex. "Una primera aproximación al Tema de la Prueba Ilícita en Chile", en: Ius et Praxis vol. $4 \mathrm{~N}^{\circ} 2$, pp. 301-322. Talca: Universidad de Talca, 1998.

CAROCCA, Alex. Garantía constitucional de la defensa procesal. Barcelona: J. M. Bosch Editor, 1998.

CAROCCA, Alex. "La defensa en el nuevo proceso penal", en: Revista Chilena de Derecho vol. 29 N² 2, pp. 283301. Santiago: Pontificia Universidad Católica de Chile, 2002.

CAROCCA, Alex. "Bases constitucionales del sistema procesal chileno", en: FERRADA BORQUEZ, Juan Carlos (Coord.). La constitucionalización del derecho chileno. Santiago: Editorial Jurídica de Chile, 2003. pp. 238 y ss.

CORPoración AdMINISTRATIVA DEL PODER Judicial. Manual de Estudio Juzgados de Letras del Trabajo. Santiago, 2007.

FaIRÉn GuILlen, Víctor. Teoria general del derecho procesal. Ciudad Universitaria: UNAM, 1992.

Ferrer Beltrán, Jordi. Prueba y verdad en el derecho. Madrid: Marcial Pons, 2002.

FERRER BeLTRÁN, Jordi. "La valoración de la prueba”, en: VV.AA. Estudios sobre la prueba. México: UNAM, 2006.

Ferrer Beltrá, Jordi. La Valoración Racional de la Prueba. Madrid: Marcial Pons, 2007.

GAMONAL, Sergio. El Procedimiento de Tutela de Derechos Laborales. Santiago: LegalPublishing, 2008.

GASCON ABELLÁN, Marina. Los hechos en el derecho. Madrid: Marcial Pons, 2004.

GÜNTHER, Klaus. "Un concepto normativo de coherencia en una teoría de la argumentación jurídica", en: DOXA N $\mathrm{N}^{\circ}$ 17-18, pp. 271-302. Alicante, 1995.

HUNTER, Iván. Las potestades probatorias del juez de familia. Santiago: LegalPublishing, 2008.

JEQUIER, Eduardo. "La obtención ilícita de la fuente de la prueba en el proceso civil. Análisis comparativo del ordenamiento jurídico español y chileno", en: Revista Chilena de Derecho, vol. 34 N$^{\circ} 3$, pp. 457-494. Santiago: Pontificia Universidad Católica de Chile, diciembre 2007.

LIZAMa, Luis y UGARTE, José Luis. Nueva Ley de Acoso Sexual. Santiago: LexisNexis, 2005.

MaCChiavello, Guido. Manual de Derecho Procesal del Trabajo. Santiago: ConoSur, 1997.

MASCIOTRA, Mario. La conducta procesal de las partes. Buenos Aires: Ad-Hoc, 2005.

Maturana, Cristián. "Los Principios que deben regir un Nuevo Proceso Civil en Chile", en: Boletín Jurídico del Ministerio de Justicia. Hacia una Nueva Justicia Civil, año 4, N²7, noviembre 2005, pp. 10-21.

MONTERO AROCA, Juan. Introducción al proceso laboral. Madrid: Marcial Pons, 2000.

NúÑeż OJEDA, Raúl. "Crónica sobre la Reforma al Sistema Procesal Civil Chileno (Fundamentos, Historia y Principios", en: De la Oliva Santos, Andrés y Palomo Vélez, Diego (coord.). Proceso Civil. Hacia una nueva justicia civil. Santiago: Editorial Jurídica de Chile, 2007.

NÚNEEZ OJEDA, Raúl. "El sistema de recursos procesales en el ámbito civil en un Estado democrático deliberativo", en: Ius et Praxis, vol. $14 \mathrm{~N}^{\circ} 1$, p. 203. Talca: Universidad de Talca, 2008.

Orellana, Fernando. Comentarios al nuevo proceso laboral -2a edición-. Santiago: Librotecnia 2009.

OtÁrola, Paulo. "Los Principios Formativos del Proceso y el Rol del Juez en el Proceso Laboral Chileno", en: Primera Jornada Chileno-Uruguaya de Derecho del Trabajo y de la Seguridad Social, Montevideo Uruguay, junio 2008.

PalaVecino, Claudio. “¿El fin justifica los medios?”, en: La Semana Juridica No 333, Santiago, 26 de marzo al 1 de abril de 2007.

Palavecino, Claudio. "Procedimiento de tutela laboral y debido proceso", en: La Semana Juridica No 336, Santiago, 11 de abril al 22 de abril de 2007. 
PALAVECINO CÁCERES, Claudio. "La carga de la prueba en el procedimiento de tutela laboral", en: La Semana Juridica No 380, Santiago, 20 de agosto al 2 de septiembre de 2008.

PALAVECINO, Claudio. "La carga de la prueba en el procedimiento de tutela laboral", en: La Semana Jurídica No 380, Santiago, 20 de agosto al 2 de septiembre de 2008.

Pérez Ragone, Álvaro; Ortiz Pradillo, Juan Carlos; Prưtting, Hans y De Falco, Sandra. Código Procesal Civil alemán $(Z P O)$. Traducción con estudio introductorio. Montevideo: Fundación Konrad-Adenauer, 2006.

Pérez Ragone, Álvaro y NúŃez, Raúl. "Nuevo Código Procesal Civil: un proyecto que acerca y simplifica la justicia”. Junio 2009. [En línea] http://www.derecho.ucv.cl/jciviljun09.pdf [Consulta 20.01.2010].

PEYRANO, Jorge. "Nuevos lineamientos de las cargas probatorias dinámicas", en: VV.AA. Cargas probatorias dinámicas. Buenos Aires: Rubinzal-Culzoni, 2008.

PEYRANO, Marcos L. "La teoría de las "cargas probatorias dinámicas" en la flamante ley de enjuiciamiento civil española (Ley 1/2000)", en: VV.AA. Cargas probatorias dinámicas. Buenos Aires: Rubinzal-Culzoni, 2008.

PICO I JUNOY, Joan. "El derecho procesal entre el garantismo y la eficacia: Un debate mal planteado", en: Montero Aroca, Juan (Coord.). Proceso civil e ideologia. Un prefacio, una sentencia, dos cartas y quince ensayos. Valencia: Tirant lo Blanch, 2006.

PICÓ I JUNOY, Joan. El juez y la prueba. Estudio de la errónea recepción del brocardo iudex iudicare debet secundum allegata et probata, non secundum conscientiam y su repercusión actual. Barcelona: Bosch, 2007.

Pulgar, Carlos. “Existe un Derecho Procesal del Trabajo?”, en: Boletin Oficial de la Dirección del Trabajo N 2005. Santiago, febrero 2006.

RAMOS MÉNDEZ, Francisco. Derecho procesal civil. Tomo I. Barcelona: JM Bosch, 1990.

ROSENBERG, Leo. La carga de la prueba. Buenos Aires: E.J.E.A, 1956.

SANTIBÁŃEZ BORIC, Cristina. "Las cargas probatorias dinámicas", en: Revista Chilena de Derecho del Trabajo y de la Seguridad Social vol. 1. No 1, pp. 83-92. Santiago: Universidad de Chile, 2010.

SCHÖNKE, Adolfo. Derecho Procesal Civil. Barcelona: Bosch Casa Editorial, 1950.

SEnTIS Melendo, Santiago. Estudios de derecho procesal. Tomo I. Buenos Aires: E.J.E.A., 1967, p. 340.

SERRA DOMÍnguez, Manuel. Estudios de derecho procesal. Barcelona: Ariel, 1969.

SILVA MONTES, Rodrigo. Manual de procedimiento laboral. Santiago: Editorial Jurídica de Chile, 2009.

STÚRNER, Rolf. Derecho procesal y culturas jurídicas, en: Ius et Praxis vol. 13 Nº 1, pp. 435-462. Talca, 2007.

STÜRNER, Rolf. "La obtención de información probatoria en el proceso civil", en: Revista de Derecho vol. 30 No1, pp. 243-262 y ss. Valparaíso: Pontificia Universidad Católica de Valparaíso, junio 2008.

TARUfFo, Michele. "Racionalidad y crisis ley procesal", en: DOXA N ${ }^{\circ} 22$, pp. 310-320, Alicante, 1999.

TARUffo, Michele. La Prueba de los Hechos. Madrid: Trotta, 2002.

TARUFFO, Michele. "Algunos comentarios sobre la valoración de la prueba", en: Discusiones $N^{\circ} 3$. Bahía Blanca, 2003.

TARuffo, Michele. "Investigación Judicial y Producción de Prueba por las Partes", en: Revista de Derecho vol. 15. Valdivia: Universidad Austral, 2003.

TARUfFo, Michele. "El proceso civil de "civil law": Aspectos fundamentales", en: Ius et Praxis vol. 12 N¹, pp. 69-94. Talca, 2006.

TARUfFo, Michele. "Poderes de las partes y del juez en Europa", en: DOXA N² 29, pp. 249-271. Alicante, 2006.

TARuffo, Michele. La prueba. Madrid: Marcial Pons, 2010.

TAVOLARI, Raúl. "Bases y criterios para el nuevo proceso civil chileno", en: DE LA OLIVA SANTOS, Andrés y PALOMO VÉlez, Diego (coord.). Proceso Civil. Hacia una nueva justicia civil. Santiago: Editorial Jurídica de Chile, 2007. 
Francisco Javier Jara Buscos./ La facilidad probatoria en el procedimiento de tutela laboral..

THAYER, William. "El nuevo procedimiento laboral. Proyecto antiguo y ley precipitada", en: Actualidad Juridica $N^{\circ} 18$, pp. 519-534. Santiago: Universidad del Desarrollo, julio 2008.

TOPASIO, Aldo. "Fundamentos históricos del principio de inexcusabilidad del juez en el devenir jurídico hispá-! nico y chileno", en: Revista Chilena de Derecho vol. 9, N², pp. 156-194. Santiago: Pontificia Universidad Católica, 1983.

Ugarte CATAlDo, José Luis. "La Turela de Derechos Fundamentales y el Derecho del Trabajo: de Erizo a Zorro", en: Revista de Derecho vol. 20 No2. Valdivia: Universidad Austral de Chile, diciembre 2007.

UGARTE, José Luis. "Tutela laboral de derechos fundamentales y carga de la prueba", en: Revista de Derecho vol. ' $33 \mathrm{~N}^{\circ}$ 2, pp. 215-228. Valparaíso: Pontificia Universidad Católica de Valparaíso, diciembre 2009.

UGARTE, José Luis. Tutela de derechos fundamentales del trabajador. Santiago: LegalPublishing, 2009.

VV.AA. Derecho Procesal del Trabajo. Treinta Estudios. Montevideo: Fundación de Cultura Universitaria, 2005.

WALTER, Rodolfo y LANATA, Gabriela. Régimen legal del nuevo proceso laboral chileno -6a edición-. Santiago: LegalPublishing, 2009. 